\title{
Validation of IEEE P1547.1 Interconnection Test Procedures: ASCO 7000 Soft Load Transfer System
}

B. Kroposki, S. Englebretson, and C. Pink National Renewable Energy Laboratory

J. Daley, R. Siciliano, and D. Hinton ASCO Power Technologies

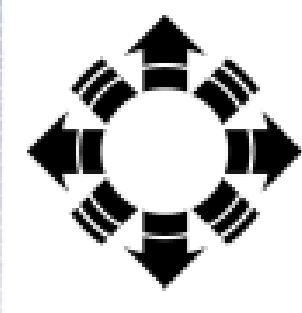

\section{NPEI}

National Renewable Energy Laboratory

1617 Cole Boulevard

Golden, Colorado 80401-3393

NREL is a U.S. Department of Energy Laboratory

Operated by Midwest Research Institute $\bullet$ Battelle $\bullet$ Bechtel

Contract No. DE-AC36-99-G010337 


\section{Validation of IEEE P1547.1 Interconnection Test}

\section{Procedures: ASCO 7000 Soft Load Transfer System}

B. Kroposki, S. Englebretson, and C. Pink National Renewable Energy Laboratory

J. Daley, R. Siciliano, and D. Hinton ASCO Power Technologies

Prepared under Task No. DP03.1001
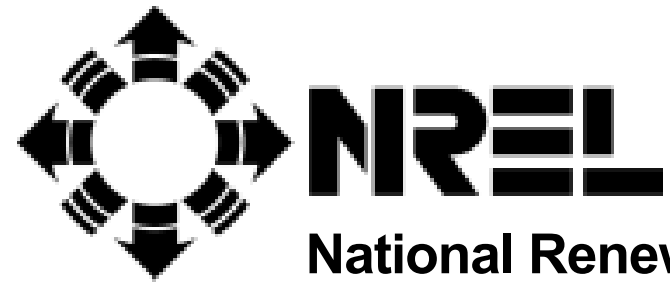

National Renewable Energy Laboratory

1617 Cole Boulevard

Golden, Colorado 80401-3393

NREL is a U.S. Department of Energy Laboratory

Operated by Midwest Research Institute • Battelle • Bechtel

Contract No. DE-AC36-99-G010337 


\section{NOTICE}

This report was prepared as an account of work sponsored by an agency of the United States government. Neither the United States government nor any agency thereof, nor any of their employees, makes any warranty, express or implied, or assumes any legal liability or responsibility for the accuracy, completeness, or usefulness of any information, apparatus, product, or process disclosed, or represents that its use would not infringe privately owned rights. Reference herein to any specific commercial product, process, or service by trade name, trademark, manufacturer, or otherwise does not necessarily constitute or imply its endorsement, recommendation, or favoring by the United States government or any agency thereof. The views and opinions of authors expressed herein do not necessarily state or reflect those of the United States government or any agency thereof.

Available electronically at http://www.osti.gov/bridge

Available for a processing fee to U.S. Department of Energy and its contractors, in paper, from:

U.S. Department of Energy

Office of Scientific and Technical Information

P.O. Box 62

Oak Ridge, TN 37831-0062

phone: 865.576 .8401

fax: 865.576.5728

email: reports@adonis.osti.gov

Available for sale to the public, in paper, from:

U.S. Department of Commerce

National Technical Information Service

5285 Port Royal Road

Springfield, VA 22161

phone: 800.553.6847

fax: 703.605.6900

email: orders@ntis.fedworld.gov

online ordering: http://www.ntis.gov/ordering.htm 


\section{Nomenclature}

A scaling factor ( $\mathrm{PU}$ is at least $110 \%$ of $\mathrm{P}_{\mathrm{T}}$ ) for step functions in time tests

a

DG

DR

EPS

manufacturer's stated accuracy for the PUT

distributed generation

distributed resources

NREL

electric power system

IEEE

$\mathrm{P}$

$\mathrm{P}_{\mathrm{b}}$

$\mathrm{P}_{\mathrm{N}}$

$\mathrm{P}_{\mathrm{T}}$

$\mathrm{P}_{\mathrm{U}}$

PUT

SLTS

National Renewable Energy Laboratory

$\mathrm{S} / \mathrm{s}$

Institute of Electrical and Electronics Engineers

parameter under test

ramp function starting value (within $10 \%$ of $\mathrm{P}_{\mathrm{T}}$ )

nominal condition

test set point

final step function value

parameter under test

Soft Load Transfer Switch

$t_{h}$

samples per second

hold time (greater than PUT time-delay setting)

$t_{i}$

ramp/step function start time

$\mathrm{ramp} / \mathrm{step}$ function end time

$t_{0}$

$\mathrm{ramp} / \mathrm{step}$ function rise time (less than $1 \%$ of PUT time-delay setting)

PUT time delay setting(s)

$\mathrm{U}$

PUT time delay setting(s) 


\section{Table of Contents}

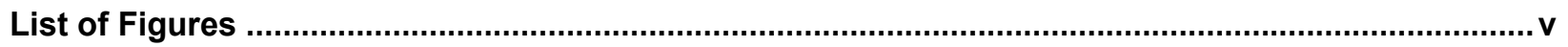

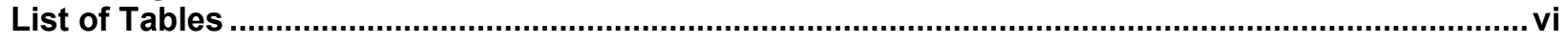

$1 \quad$ Background

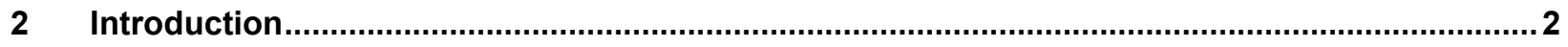

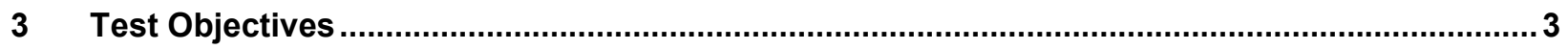

$4 \quad$ System Configuration and Electrical Equipment............................................................... 4

4.1 Electrical System Configuration .............................................................................. 4

4.2 The ASCO 7000 Series Soft Load Power Transfer Switch ........................................ 5

4.3 Data Acquisition System..................................................................................... 7

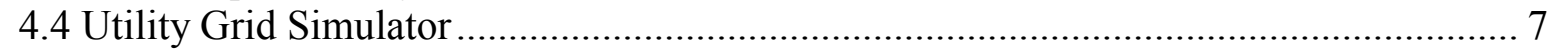

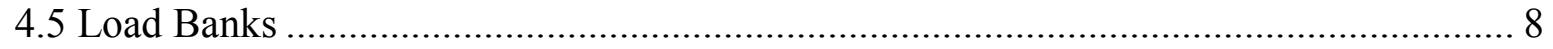

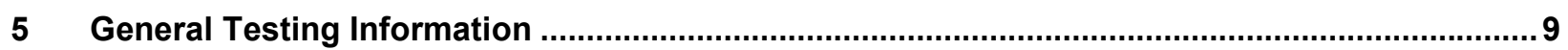

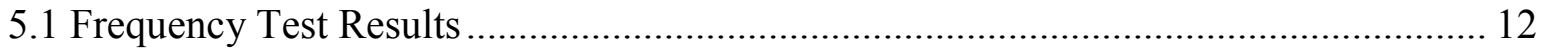

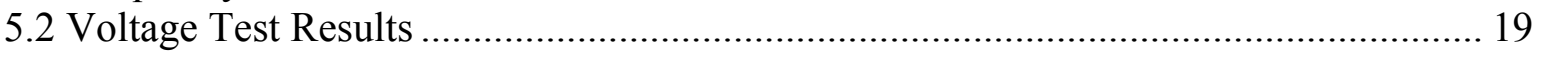

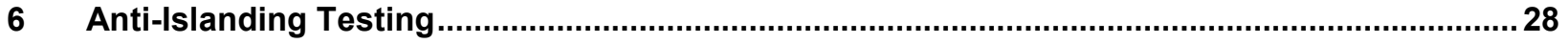

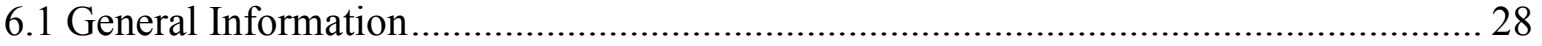

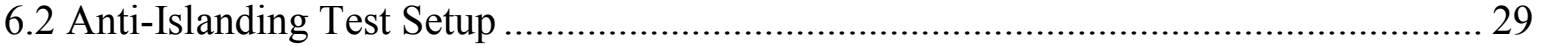

6.3 Anti-Islanding Test Results............................................................................. 30

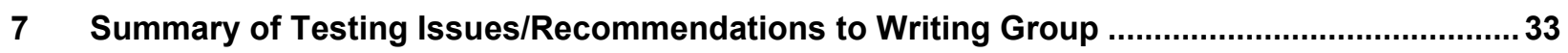

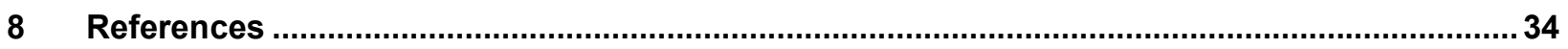

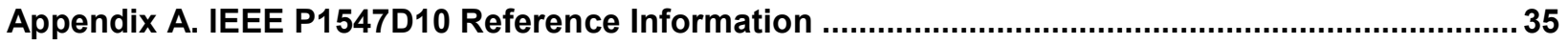

Appendix B. Abnormal Frequency and Voltage Test Results .......................................................... 36

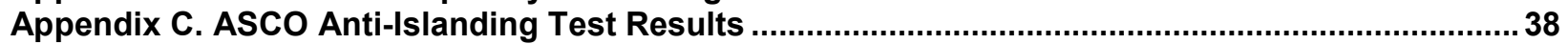

Appendix D. ASCO Single-Phase Anti-Islanding Test Results ........................................................4 44 


\section{List of Figures}

Figure 1. NREL DER Test Facility ……………………….............................................. 1

Figure 2. DG interconnection monitoring and test platform setup for ASCO SLTS testing ....... 4

Figure 3. ASCO SLTS front panel display..................................................................... 5

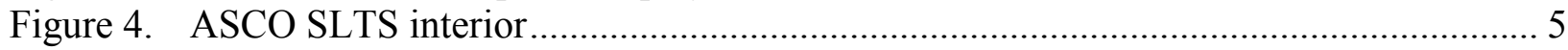

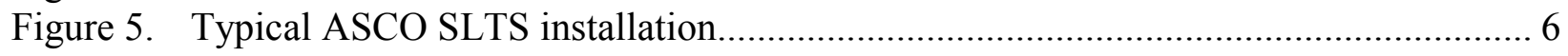

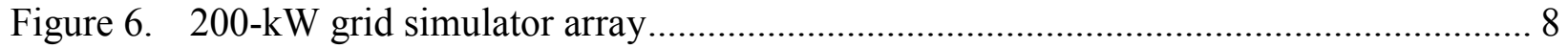

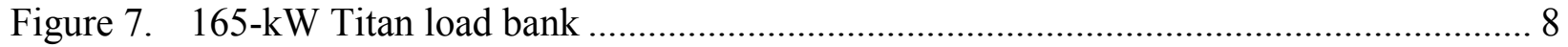

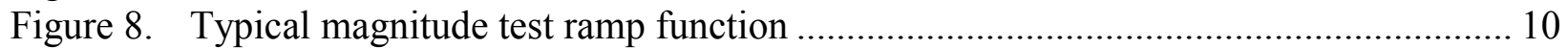

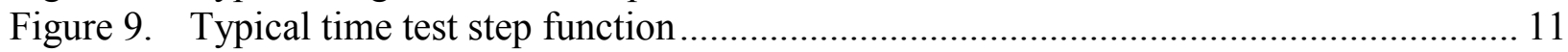

Figure 10. Overfrequency ramp function ............................................................................. 13

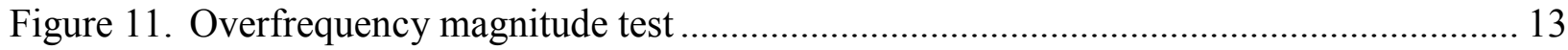

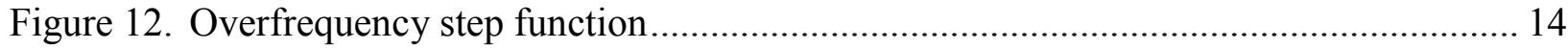

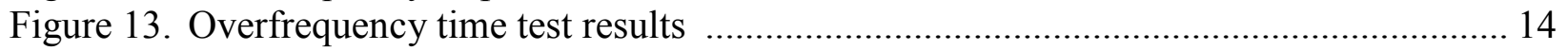

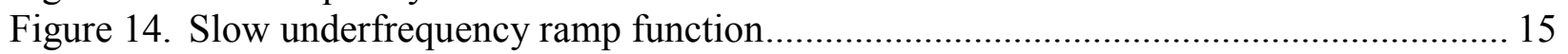

Figure 15. Underfrequency magnitude test results............................................................... 15

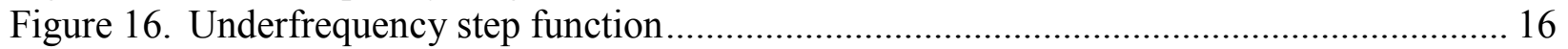

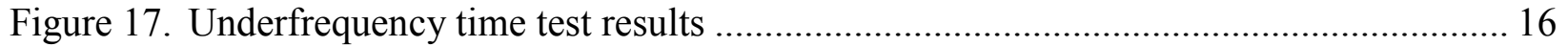

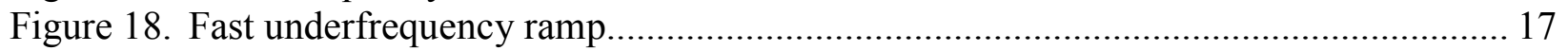

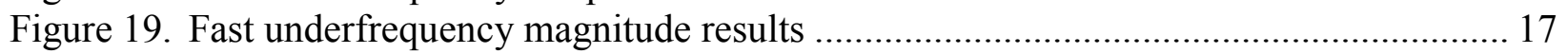

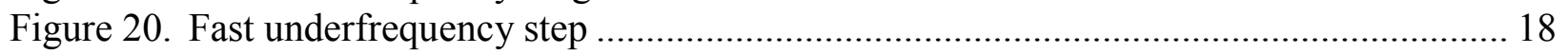

Figure 21. Fast underfrequency time test results................................................................ 18

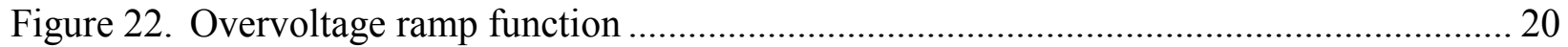

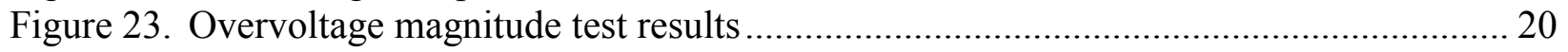

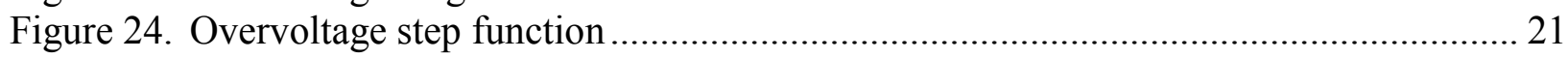

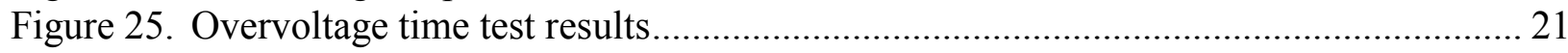

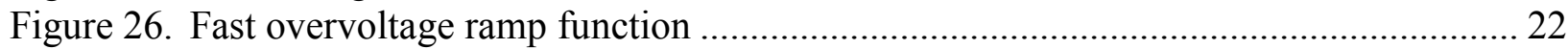

Figure 27. Fast overvoltage magnitude test results .............................................................. 22

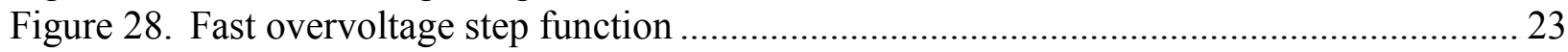

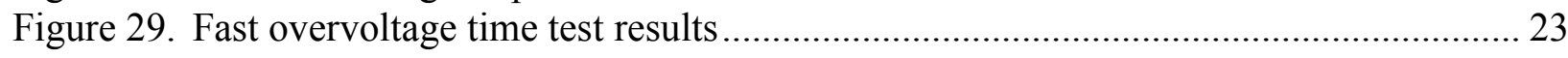

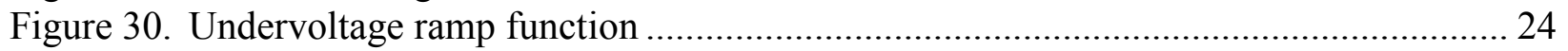

Figure 31. Undervoltage magnitude test results ........................................................................ 24

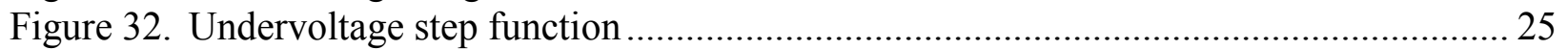

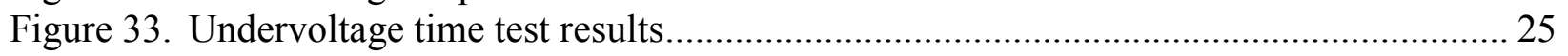

Figure 34. Fast undervoltage ramp function ......................................................................... 26

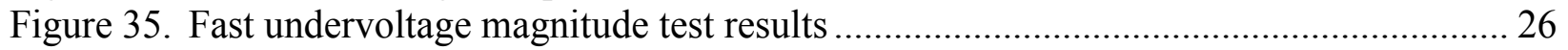

Figure 36. Fast undervoltage step function ...................................................................... 27

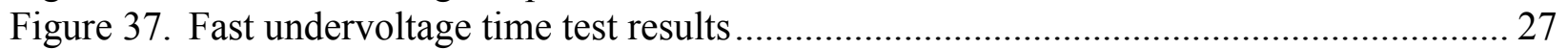

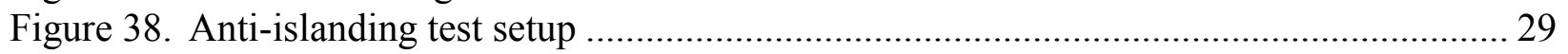

Figure 39. Anti-islanding clearing times comparison ........................................................... 30

Figure 40. Power factor effect on anti-islanding loss of phase ................................................... 31 


\section{List of Tables}

Table 1. ASCO Adjustable Protective Function Settings ……............................................. 7

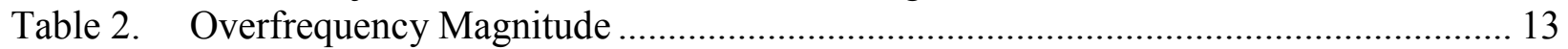

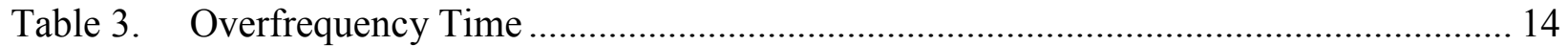

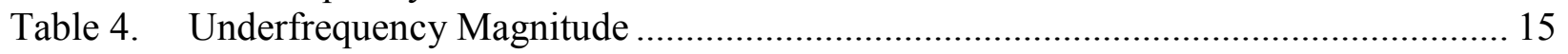

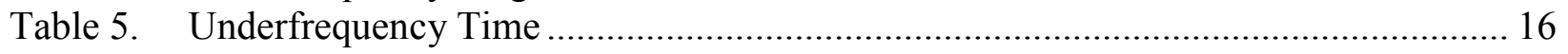

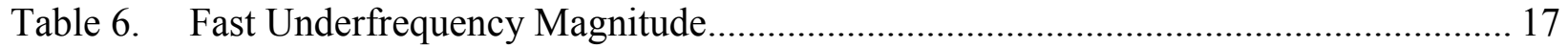

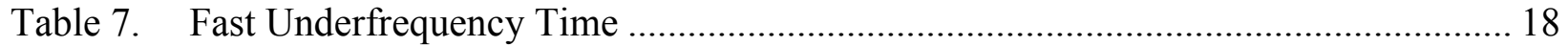

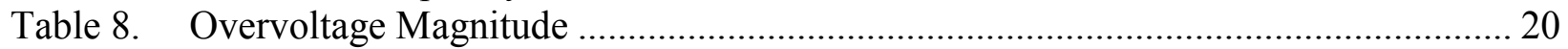

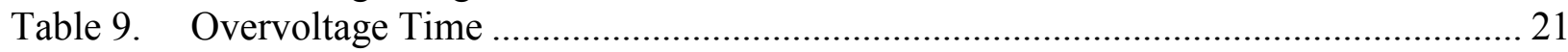

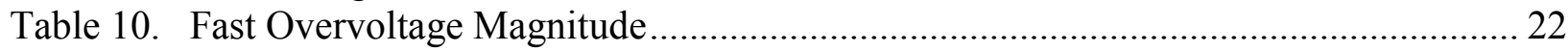

Table 11. Fast Overvoltage Time

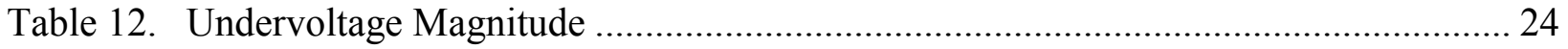

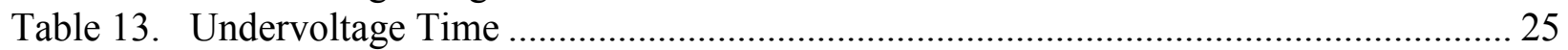

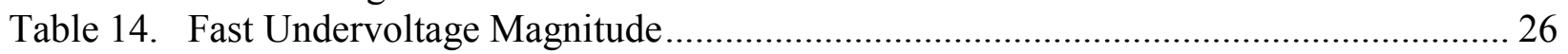

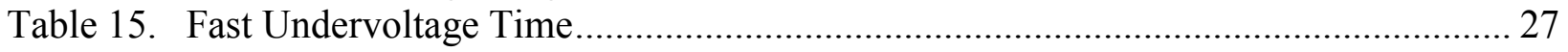

Table 16. Summary of Loss of Phase Results........................................................................ 32

Table A-1. Interconnection System Response to Abnormal Voltages .......................................... 35

Table A-2. Interconnection System Response to Abnormal Frequencies ...................................... 35

Table B-1. Abnormal Frequency and Voltage Test Results ........................................................ 36

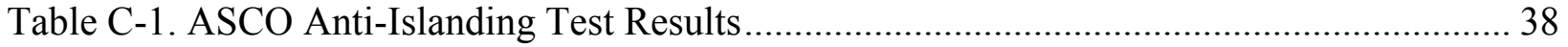

Table D-1. ASCO Single-Phase Anti-Islanding Test Results...................................................... 44 


\section{Background}

The Distributed Power Systems Integration Team at the National Renewable Energy Laboratory (NREL) has been instrumental in the effort to develop standard interconnection requirements for distributed resources (DR). DR are generation and storage located at or near the point of use. Examples include photovoltaics, wind turbines, microturbines, fuel cells, and internal combustion engines. When interconnected with the electric power system (EPS) at or near load centers, these technologies can provide increased efficiency, availability, reliability, and power quality as well as a variety of economic and power system benefits.

However, many obstacles have been encountered in the pursuit of these benefits. Confusion and division arise from differences of experience and expertise as well as from the wide variety of existing interconnection standards and requirements of utility, state, and regional organizations.

The Institute of Electrical and Electronics Engineers (IEEE) has created the IEEE 1547 Standard for Interconnecting Distributed Resources With Electric Power Systems and is developing the accompanying P1547.1 Draft Conformance Test Procedures, P1547.2 Draft Application Guide, and P1547.3 Draft Guide for Monitoring, Information Exchange, and Control to help overcome the challenges facing DR. These standards are created through collaboration and agreement among experts from all related fields, including utilities, equipment manufacturers, and government laboratories. The IEEE 1547 consensus standard contains specific requirements related to the performance, operation, testing, safety, and maintenance of interconnections between DR and EPSs. Uniform interconnection requirements should help all parties realize the benefits of DR while saving time, money, and headache.

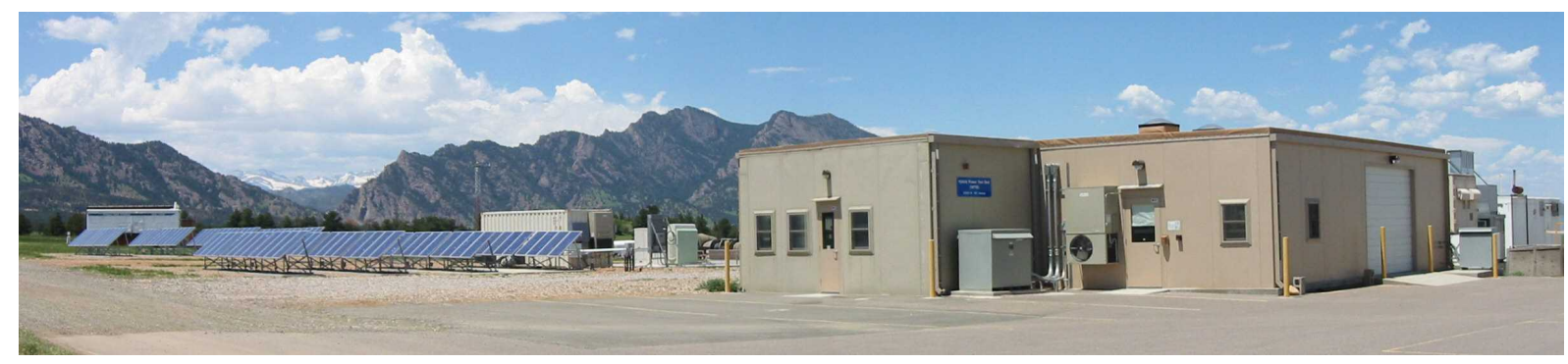

Figure 1. NREL DER Test Facility

Validation of the conformance test procedures from IEEE P1547.1 is being conducted at the NREL Distributed Energy Resources Test Facility near Boulder, Colorado (Figure 1). Although still under development, draft standard P1547.1 lists specific test procedures to demonstrate that DR interconnected with EPSs meet the requirements stated in IEEE 1547.

This report details the procedures of and results from testing the ASCO 7000 Soft Load Transfer Switch (SLTS) according to P1547.1 Draft 2. The ASCO device is designed to integrate synchronous generators with the utility grid. These generators can be integrated as emergency backup for power outages or parallel to the grid to reduce local load and corresponding energy costs. 


\section{Introduction}

This report presents the preliminary results of testing the ASCO 7000 SLTS according to IEEE P1547.1 procedures. The ASCO SLTS interconnects synchronous generators with the EPS and provides monitoring and control for the generator and grid connection through extensive protective functions. This work continues efforts started in 2001 at the Nevada Test Site to demonstrate the validity of the 1547 interconnection tests and requirements. The purpose of this testing is to evaluate and give feedback on the contents of IEEE Draft Standard P1547.1 Conformance Tests Procedures for Equipment Interconnecting Distributed Resources With Electric Power Systems.

IEEE P1547.1 is one of three standards in progress to accompany IEEE 1547 Standard for Interconnecting Distributed Resources With Electric Power Systems. P1547.1 is intended to provide test procedures for verifying distributed generation (DG) equipment conformance to 1547. As part of an effort to validate and refine the procedures being developed for P1547.1, more detailed testing was conducted on an ASCO 7000 SLTS based on P1547.1 Draft 2. The following is a summary of the testing and results, focusing on the ASCO response to over and underfrequency, over and undervoltage, and unintentional islanding. 


\section{$3 \quad$ Test Objectives}

The objective of these tests is to validate some of the interconnection test procedures under development for IEEE P1547.1 Draft 2. The tests include response to abnormal voltage and frequency conditions as well as to unintentional islanding. These results will be shared with the P1547.1 working group to help in the development of the final test procedures for compliance to IEEE 1547. 


\section{$4 \quad$ System Configuration and Electrical Equipment}

\subsection{Electrical System Configuration}

NREL's Distributed Energy Resources Test Facility provided the platform used in these tests. It includes a DG interconnection monitoring system and test switchboard that facilitates connecting a utility source, a DG source, and an emergency load bus. The ASCO SLTS, a 200-kW grid simulator, a $125-\mathrm{kW}$ diesel generator, a $100-\mathrm{kW}$ real load bank, and a $200-\mathrm{kW}$ real and reactive (inductive and capacitive) load bank were incorporated into the switchboard as shown in Figure 2.

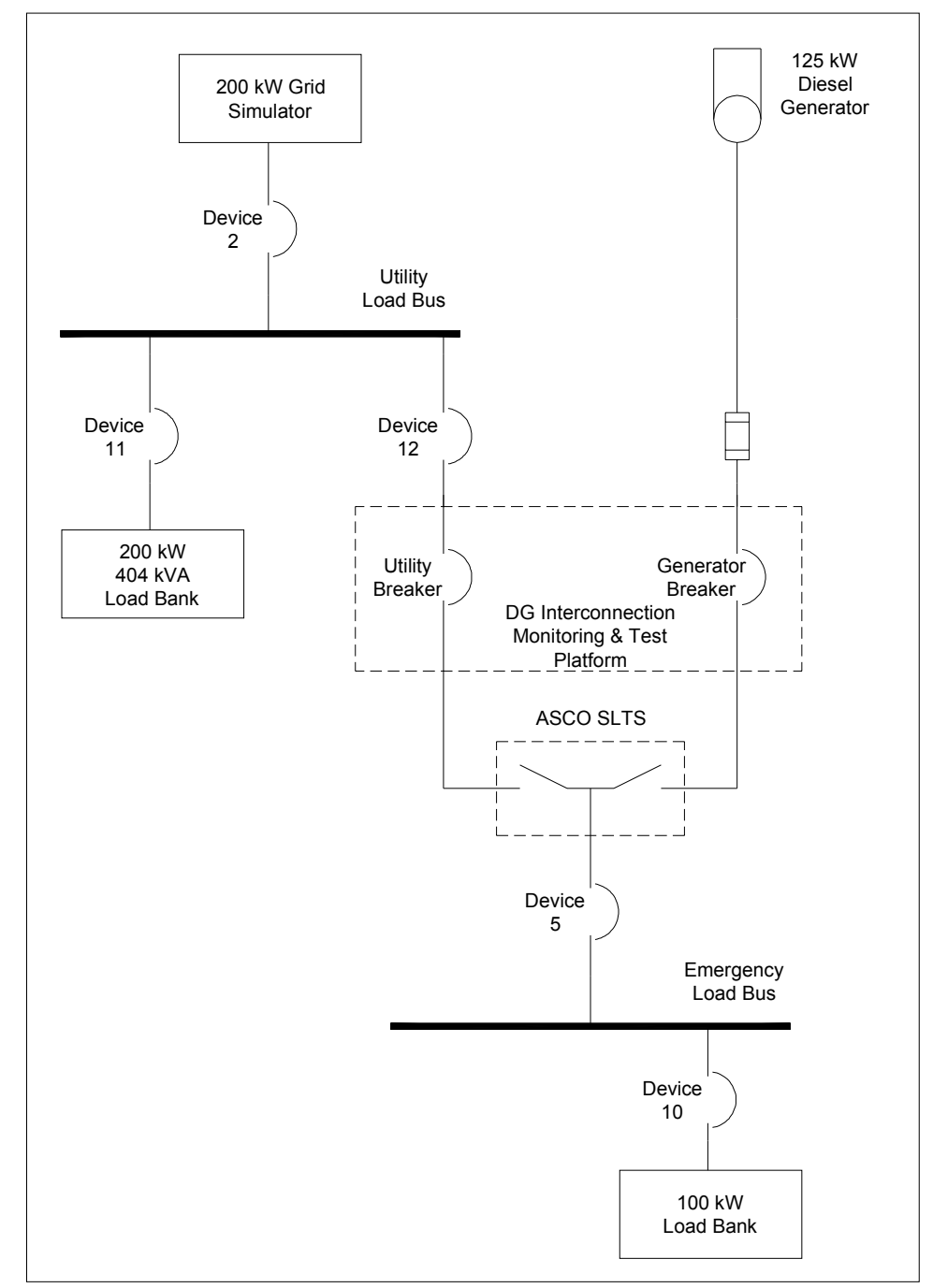

Figure 2. DG interconnection monitoring and test platform setup for ASCO SLTS testing

As stated earlier, the ASCO SLTS controls the interconnection between the DG, a 125-kW diesel generator in this case, and the "utility" or "EPS," a utility grid simulator here. The ASCO unit assumes voltage and frequency control of the diesel generator, allowing it to parallel and share load with the utility. Also, by controlling the shunt trip signal to the utility breaker, the ASCO unit manages the connection at the point of common coupling, where the local EPS connects to the entire grid. 


\subsection{The ASCO 7000 Series Soft Load Power Transfer Switch}
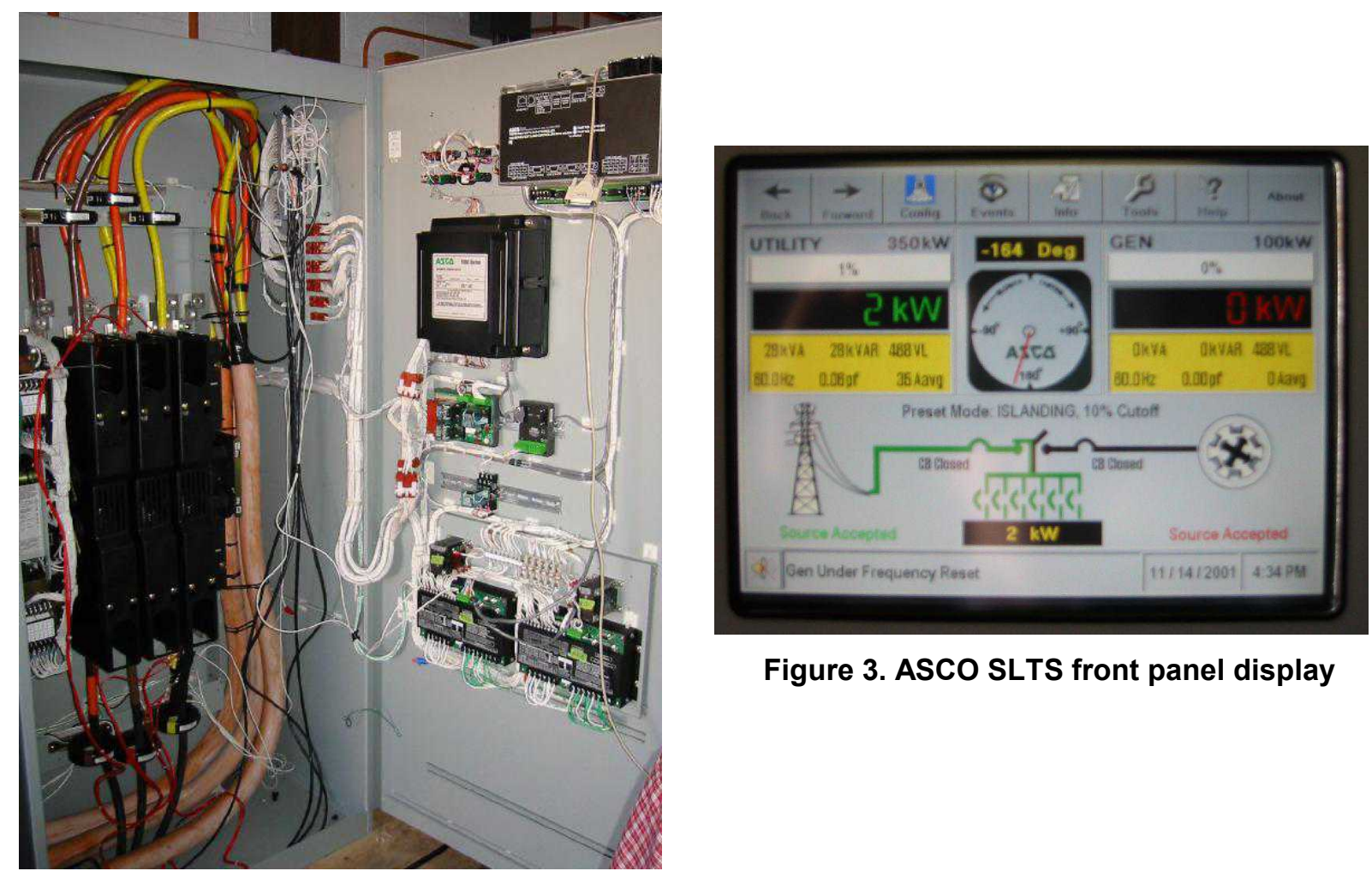

Figure 3. ASCO SLTS front panel display

Figure 4. ASCO SLTS interior

The ASCO 7000 SLTS is designed to provide a safe and controllable interconnection of the EPS, a synchronous generator, and load. This interconnection switch has traditionally been used for emergency power applications but is increasingly being used for grid-parallel operation. Avoiding significant voltage or frequency transients, the ASCO SLTS can seamlessly transfer or share load between the generator and utility bus. This allows multiple operational modes, including:

- Utility load curtailment

- Generator base loading

- Utility import level based loading.

The setup employed for the ASCO SLTS is typical of devices used to interconnect DG equipment with utility busses and therefore provides a suitably general platform for the development and verification of standard test procedures. A typical installation of an ASCO SLTS is shown schematically in Figure 5. Both the utility and generator breakers shown have shunt trips. The output of the auxiliary contact of the utility shunt trip breaker is used as a trigger for capturing testing data. 


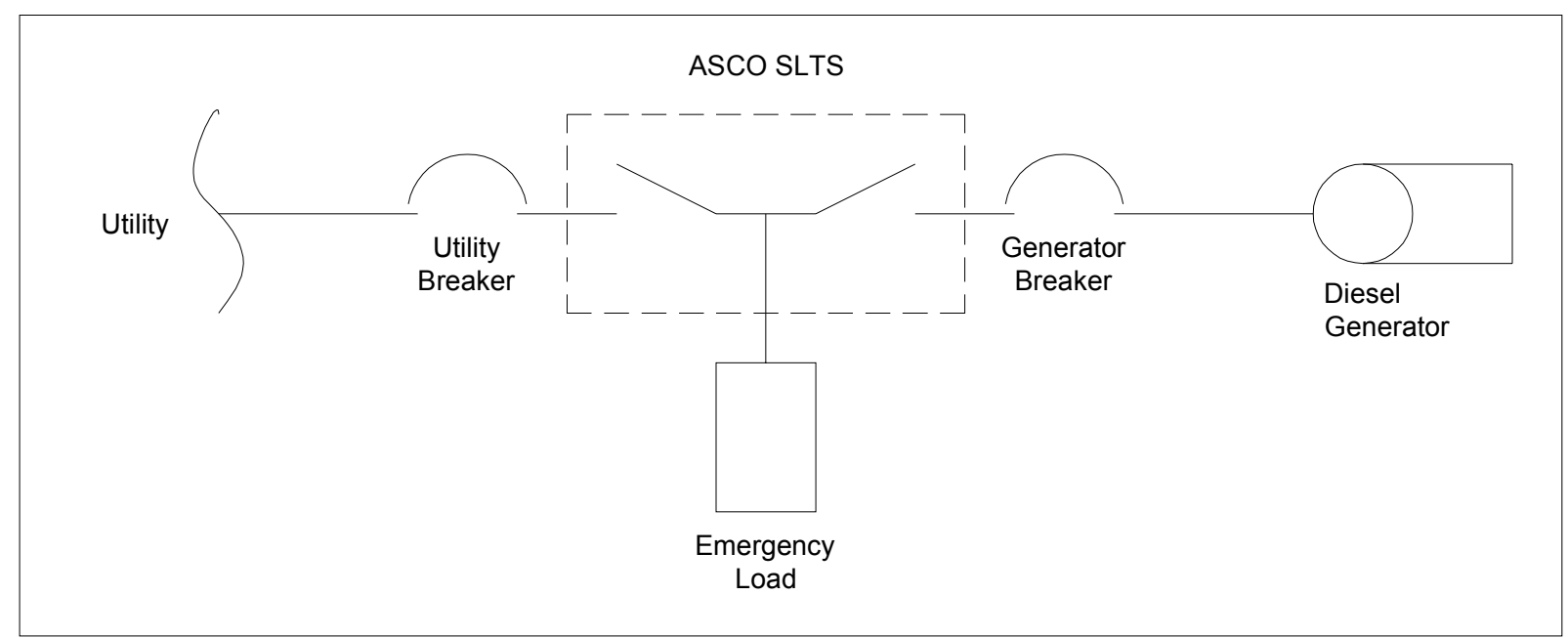

Figure 5. Typical ASCO SLTS installation

Additional features of the ASCO 7000 SLTS include:

- No voltage or frequency disruption in load transfers between the DG and EPS/utility

- Automatic transfer to onsite generation should utility power fail

- User-friendly graphical user interface to facilitate monitoring and control

- Extensive, programmable protection functions

- Ability to synchronize the DG with the EPS and control generator output and power factor.

The ASCO SLTS has a variety of protective relay functions, and many have adjustable tolerance ranges through the ASCO controls. These include:

- Overvoltage and undervoltage

- Overfrequency and underfrequency

- Reverse power and underpower

- Negative sequence voltage and current

- Directional overcurrent

- Loss of excitation.

The adjustable ranges for some of these functions are given in Table 1. Also, ASCO has developed a proprietary algorithm for detecting and disconnecting a generator during an island condition within the 2-second interval required by IEEE 1547. 
Table 1. ASCO Adjustable Protective Function Settings

\begin{tabular}{ccc}
\hline \multicolumn{3}{c}{ Adjustable Protection Settings: Percent Nominal Magnitudes } \\
Function & Dropout/Trip & Pickup/Restore \\
\cline { 2 - 3 } Undervoltage & $70 \%-98 \%$ & $85 \%-100 \%$ \\
Overvoltage & $102 \%-115 \%$ & $2 \%$ below trip \\
Underfrequency & $85 \%-98 \%$ & $90 \%-100 \%$ \\
Overfrequency & $102 \%-110 \%$ & $2 \%$ below trip \\
Voltage unbalance & $5 \%-20 \%$ & $1 \%$ below dropout \\
\hline
\end{tabular}

\subsection{Data Acquisition System}

Because many of the parameters tested involve subcycle transient times, a relatively high-speed data acquisition system was necessary to perform testing. A Yokogawa PZ4000 power analyzer was used to collect data. The PZ4000 is capable of sampling rates up to 5 million samples per second (S/s). For this testing, however, sampling rates range from 10,000 to $250,000 \mathrm{~S} / \mathrm{s}$. The PZ4000 voltage and current measurements are accurate to $\pm 0.2 \%$ of the reading values with a time scale accuracy of $\pm 0.05 \%$. The Yokogawa PZ4000 was extremely useful in this application for saving the data as both data files and bitmap images of the scope display.

\subsection{Utility Grid Simulator}

An array of four Pacific Power Source grid simulators (see Figure 6) was used to perform controlled simulations of various grid failure conditions. Four units (model number 3060-MS) were paralleled to provide a combined capacity of $250 \mathrm{kVA}(200 \mathrm{~kW})$ at 120/208 V. The Pacific Power Source 3060-MS is a double-conversion power source. Commercial input power is rectified and then converted to precision AC power through high-frequency, pulse-width modulation. This design allows fully programmable control of individual phase voltage, current, and frequency. Output regulation and total harmonic distortion are less than $1 \%$ for normal $60-\mathrm{Hz}$ operations. The $3060-\mathrm{MS}$ is capable of fast response times, reacting to a $100 \%$ step load change in less than 300 $\mu \mathrm{s}$. All four units are controlled via a master-slave arrangement that allows all units to operate simultaneously. Each unit is rated at $62.5 \mathrm{kVA}$ and is capable of delivering power at frequencies from $50 \mathrm{~Hz}$ to $400 \mathrm{~Hz}$. The output of the four-unit array is connected to a $125: 277-\mathrm{V}$ wye autotransformer to provide a three-phase, $480-\mathrm{V}_{\mathrm{L}-\mathrm{L}}$ output. 


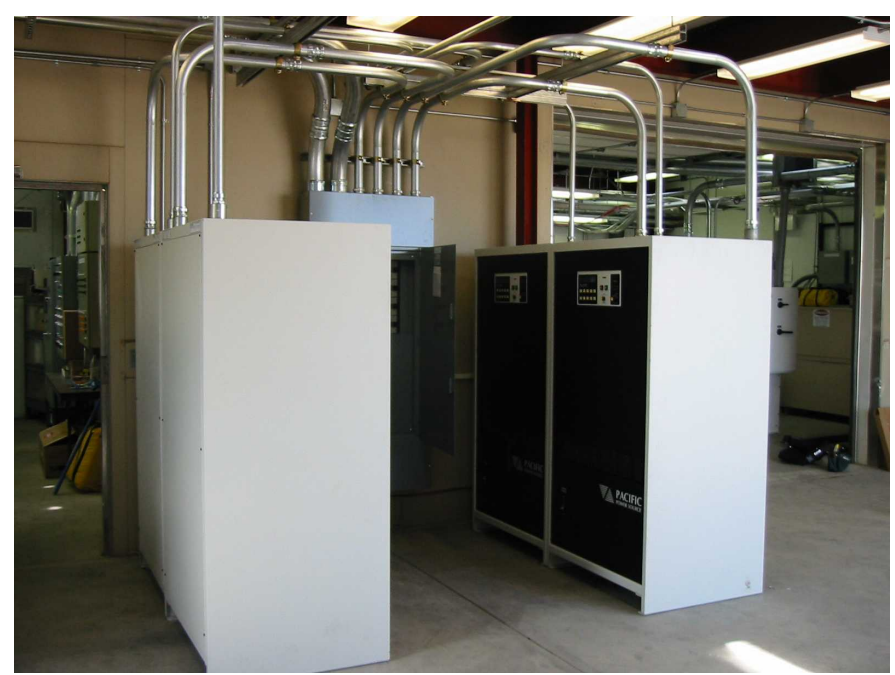

Figure 6. 200-kW grid simulator array

\subsection{Load Banks}

The load bank used for these tests is a customized version of the Simplex Titan model, shown in Figure 7. This unit was modified to provide $165 \mathrm{~kW}$ real and $404 \mathrm{kVAR}$ inductive and capacitive loads in step sizes as small as $125 \mathrm{~W}$ and 312.5 VAR. A LabView graphical user interface controls the unit through serial ports.

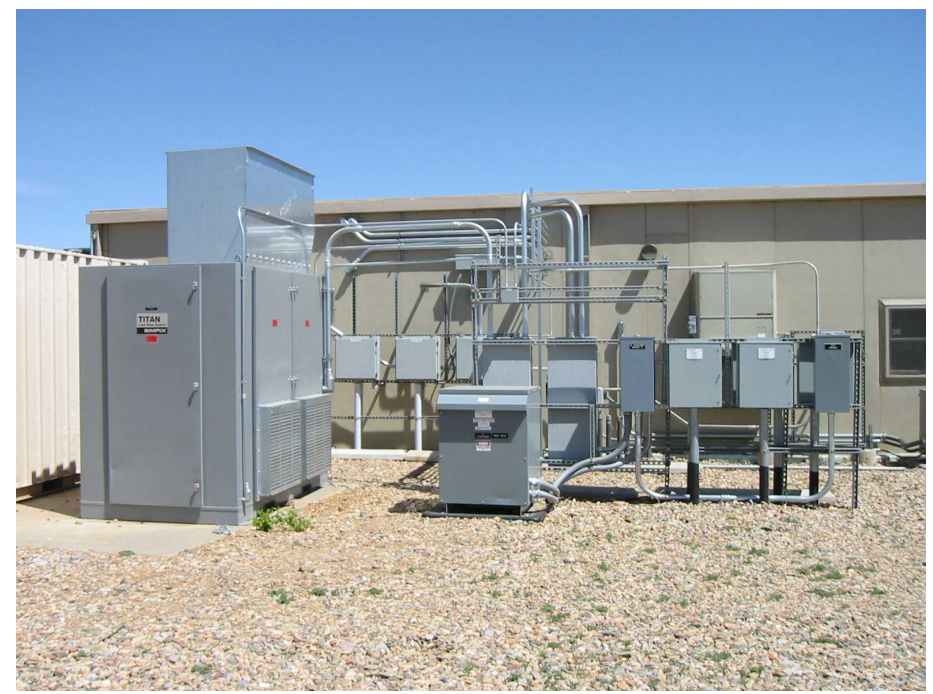

Figure 7. 165-kW Titan load bank (on left) 


\section{$5 \quad$ General Testing Information}

IEEE 1547 designates a variety of system conditions under which a distributed resource should disconnect from the utility grid. For these tests, the utility breaker from Figure 5 functions as the point of common coupling and primary disconnect. The ASCO unit meets IEEE 1547 interconnection requirements by monitoring power conditions and sending a trip signal to the utility breaker after detecting any value outside of preset ranges.

The grid simulators were used to establish the test conditions. Only the parameter under test (PUT) was allowed to vary for each test. After establishing a certain test condition (undervoltage, overfrequency, unintentional island, etc.), the ASCO must trip the utility breaker to disconnect the DG from the utility system in less than the time required by IEEE 1547 . This report details the procedures and results of testing the DG for response to abnormal voltage, abnormal frequency, and unintentional islanding conditions. The ASCO successfully disconnected the diesel generator well within the required times for all the abnormal voltage and frequency tests.

Adhering to IEEE P1547.1 Draft 2 sections 4.7.1 and 4.7.2, both a magnitude and a time test were performed for the voltage and frequency response. The function of the magnitude test was to determine the actual trip point. This was accomplished by varying the PUT in tiny increments gradually approaching the trip set point. The slow approach accounts for any time delays and ensures that the bus conditions at the time of the trip are virtually identical to the actual trip magnitudes. Ramp functions from IEEE P1547.1 and consistent with Figure 8 were programmed into and executed by the grid simulator. A description of the variables used in Figure 8 is given following the equations used to calculate the ramp functions.

$$
\begin{aligned}
& P(t)=m \cdot\left(t-t_{0}\right)+P_{b} \\
& m=\frac{(0.1 \cdot a)}{(4 \cdot z)}
\end{aligned}
$$

Where:

$$
\begin{aligned}
& \mathrm{P}=\text { PUT } \\
& \mathrm{P}_{\mathrm{N}}=\text { Nominal condition } \\
& \mathrm{P}_{\mathrm{b}}=\text { Ramp function starting value (within 10\% of } \mathrm{P}_{\mathrm{T}} \text { ) } \\
& \mathrm{P}_{\mathrm{T}}=\text { Test set point } \\
& \mathrm{t}_{\mathrm{h}}=\text { Hold time (greater than PUT time-delay setting) } \\
& \mathrm{t}_{\mathrm{o}}=\text { Ramp function start time } \\
& \mathrm{a} \quad=\text { Manufacturer's stated accuracy for PUT } \\
& \mathrm{z}=\text { Trip operating time }(\mathrm{s})
\end{aligned}
$$




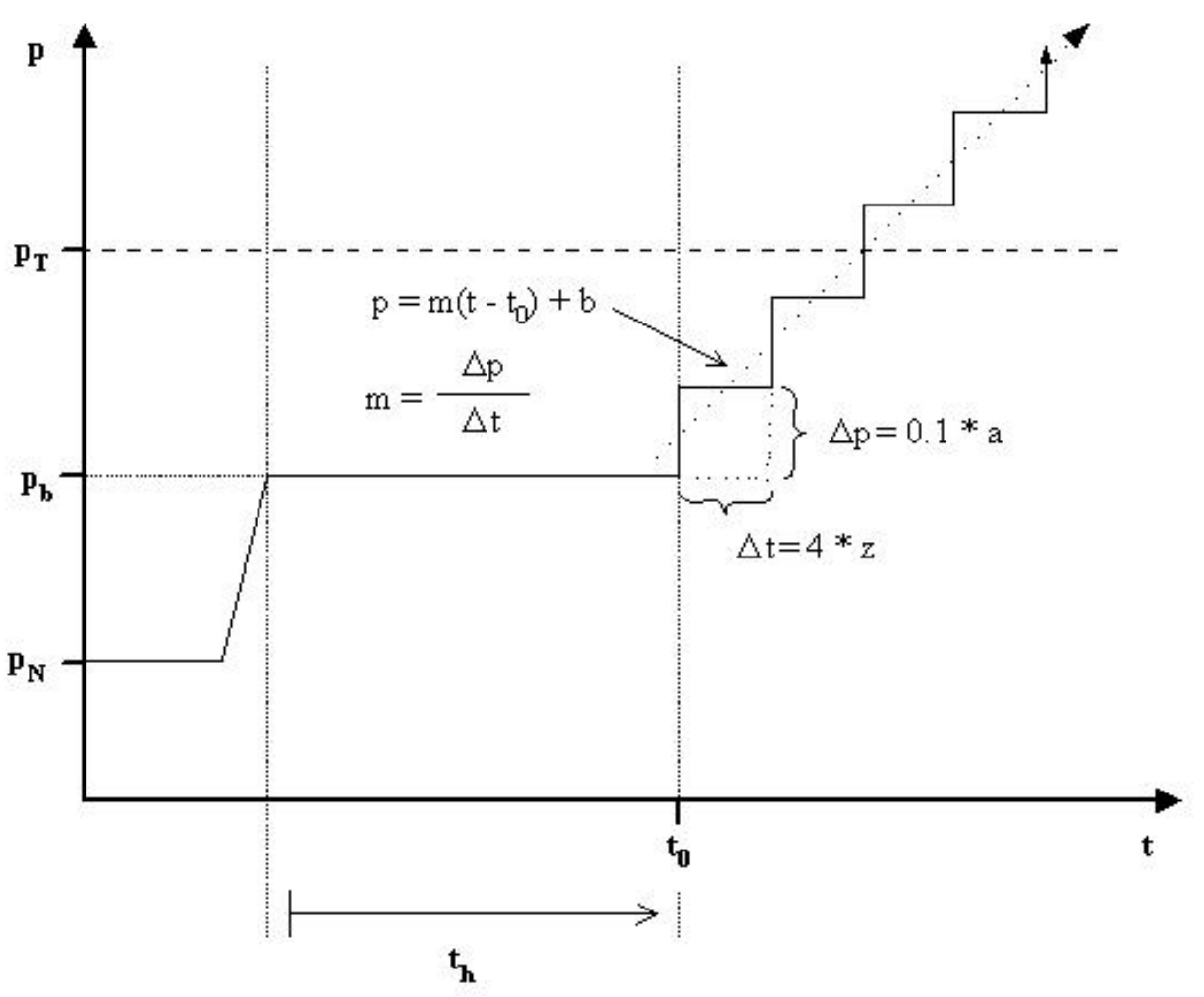

Figure 8. Typical magnitude test ramp function

Confusion arose during testing as to the proper value of " $z$ " for the ramp functions. For these tests, z- the "manufacturer's stated operating time," which is defined as "the length of time for the equipment under test's output to change state (trigger a fault condition) based on an out-oftolerance condition for the PUT"- was mistakenly assumed to be the time delay setting for each parameter. The time delay settings are variable from "instantaneous" to above $2 \mathrm{~s}$. The operating time " $\mathrm{z}$ " is a fixed value of the fastest possible time for the ASCO unit to detect and trip on an outof-tolerance condition without any added time delay. Even with the ASCO time delay set to "instantaneous," there is some delay for the breaker to trip. For this setup, that minimum operating time, the " $\mathrm{z}$ " value, is about $0.05 \mathrm{~s}$, and this number should have been used in the slope calculation for all of the magnitude test ramp functions.

After finding the trip magnitude, the time tests were used to determine the time until the device tripped once the trip conditions, as determined in the magnitude test, were established. Figure 9 shows a typical time test step function. The idea is to quickly step from below to above (ordinarily at least $10 \%$ above) the trip magnitude fast enough to know when the parameter jumps out of bounds and to avoid introducing significant delays into the trip time. The equations and a description of the variables used to calculate the ramp functions follow. 
$P(t)=A \cdot u\left(t-t_{i}\right)+P_{b}$

Where:

$\mathrm{P} \quad=\mathrm{PUT}$

$\mathrm{P}_{\mathrm{N}}=$ Nominal condition

$\mathrm{P}_{\mathrm{b}} \quad=$ Ramp function starting value (within $10 \%$ of $\mathrm{P}_{\mathrm{T}}$ )

$\mathrm{P}_{\mathrm{T}} \quad=$ Test set point

$\mathrm{P}_{\mathrm{U}}=$ Final step function value

$\mathrm{t}_{\mathrm{h}}=$ Hold time (greater than PUT time-delay setting)

$\mathrm{t}_{\mathrm{i}} \quad=$ Ramp function start time

$\mathrm{t}_{\mathrm{o}} \quad=$ Ramp function end time

$\mathrm{t}_{\mathrm{r}} \quad=$ Ramp function rise time (less than $1 \%$ of PUT time-delay setting)

A $=$ Scaling factor $\left(\mathrm{P}_{\mathrm{U}}\right.$ is at least $110 \%$ of $\left.\mathrm{P}_{\mathrm{T}}\right)$

$\mathrm{U}=$ Operating time $(\mathrm{s})$

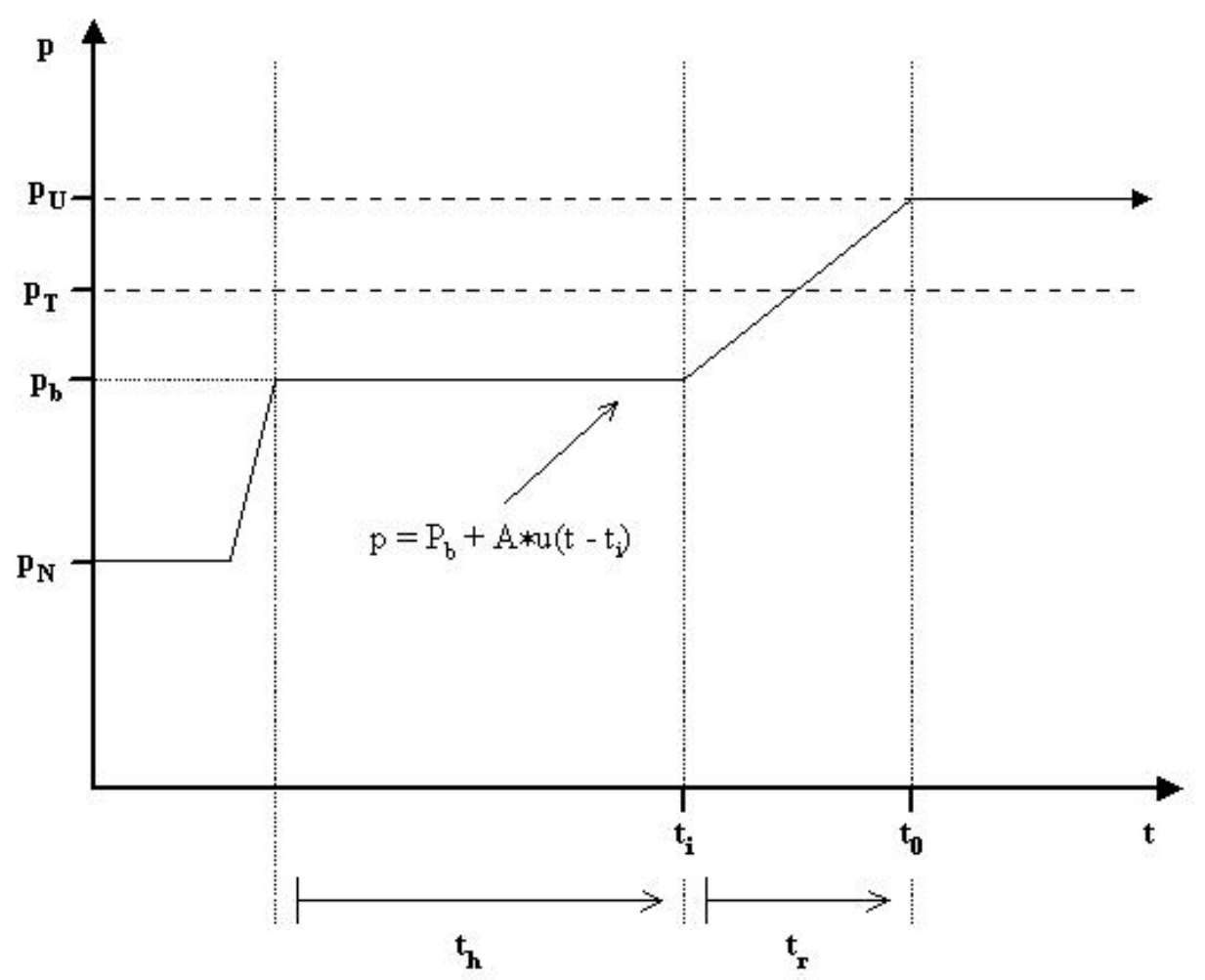

Figure 9. Typical time test step function 


\subsection{Frequency Test Results}

\subsubsection{General Testing Information}

The following is a description of the under and overfrequency tests on the ASCO SLTS, including method, results, and explanation of any issues encountered.

The general conditions established for these tests were:

- The ASCO unit paralleled the $125-\mathrm{kW}$ diesel generator to the simulated utility grid and closed all breakers.

- Load was added first to the utility bus $\left(\mathrm{P}_{\text {util }}\right)$ and then to the common bus. Both the utility and the DG are connected to the common load, shown as "emergency load" in Figure 5, through the ASCO breakers. Initially, the grid simulators fully supplied both loads.

- The ASCO SLTS then controlled the diesel generator power export ( $\left.\mathrm{P}_{\text {export }}\right)$ to assume the entire local load and to export some power back to the utility load.

Under these conditions, the ASCO unit controlled the diesel frequency to maintain $\mathrm{P}_{\text {export }}$. So by maintaining the grid simulator rate of frequency change below the time response of the diesel governor, $\mathrm{P}_{\text {export }}$ could be held constant while bus frequency was decreased or increased. 


\subsubsection{Overfrequency Magnitude}

For the overfrequency tests, the utility supplied $25 \mathrm{~kW}$ of a $30-\mathrm{kW}$ utility-side load, and the diesel powered a separate $30-\mathrm{kW}$ local load and exported $5 \mathrm{~kW}$ back to the utility load. The grid simulator varied the frequency according to the ramp function shown in Table 2.

Table 2. Overfrequency Magnitude

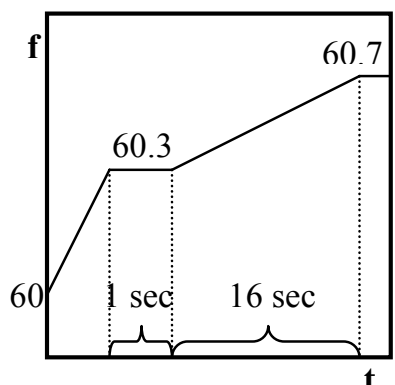

Figure 10. Overfrequency ramp function
Overfrequency Magnitude

Trial Number Trip Frequency

$\begin{array}{ll}1 & 60.458 \\ 2 & 60.604 \\ 3 & 60.461 \\ 4 & 60.534 \\ 5 & 60.531\end{array}$

\begin{tabular}{lr} 
Average & 60.518 \\
Setting & 60.5 \\
\hline
\end{tabular}

The output of the auxiliary contact of the shunt trip utility breaker was used as the trigger for testing. By measuring the period of the last cycle before tripping, the Yokogawa scope found the trip frequency. Figure 11 shows the Yokogawa display following this test. Table 2 shows how the results compare with the $60.5-\mathrm{Hz}$ overfrequency setting on the ASCO SLTS.

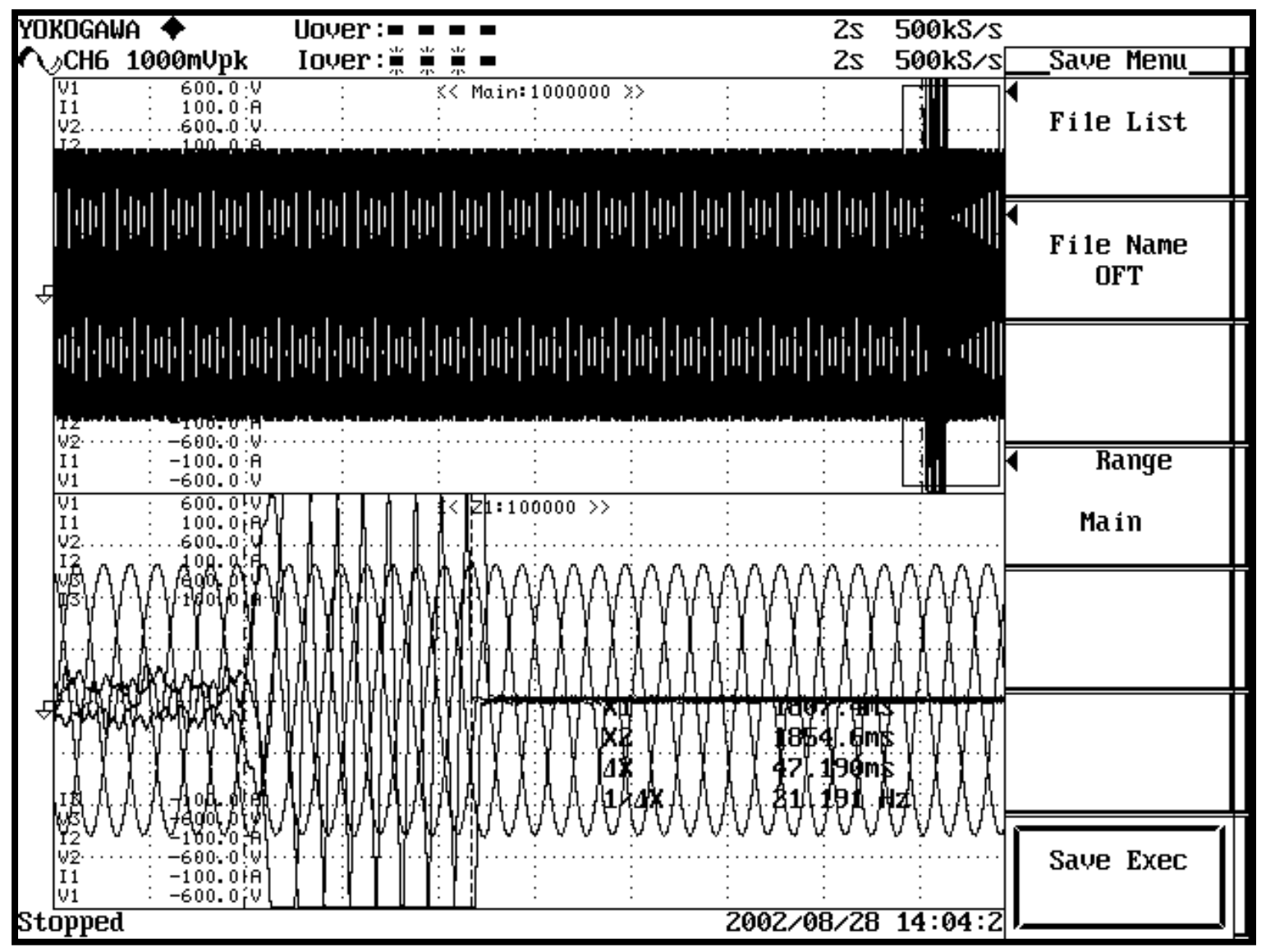

Figure 11. Overfrequency magnitude test 


\subsubsection{Overfrequency Time}

Having determined the trip magnitude, the next task was to measure the time for the ASCO unit to disconnect the DG after the overfrequency magnitude was reached. The step function shown in Figure 12 was programmed into and executed by the grid simulator to almost instantly jump from below to above the overfrequency threshold. Using $110 \%$ of $\mathrm{P}_{\mathrm{T}}$ (the trip magnitude, 60.5 $\mathrm{Hz}$ here) for $\mathrm{P}_{\mathrm{U}}$ (the final limit for the step in the time test) caused the ASCO utility breaker to trip on a variety of protective functions. To trip only on underfrequency, a $\mathrm{P}_{\mathrm{U}}$ of about $100.5 \%$ of $\mathrm{P}_{\mathrm{T}}$ was used for the time test. The ASCO disconnected the DG in $45 \mathrm{~ms}$, well under the 160 ms required by IEEE 1547. The results from Trial 2 are shown in Figure 13. The two dotted lines measure the time between the frequency step and the disconnect.

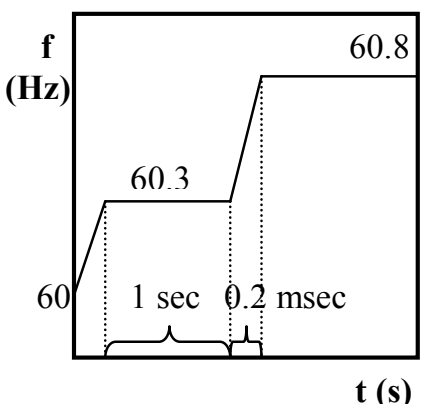

Figure 12. Overfrequency step function
Table 3. Overfrequency Time

\begin{tabular}{cc}
\hline \multicolumn{2}{c}{ Overfrequency Time } \\
Trial Number & Trip Time (ms) \\
\cline { 2 - 2 } 1 & 47 \\
2 & 58 \\
3 & 40 \\
4 & 40 \\
5 & 39
\end{tabular}

Average

45

Required

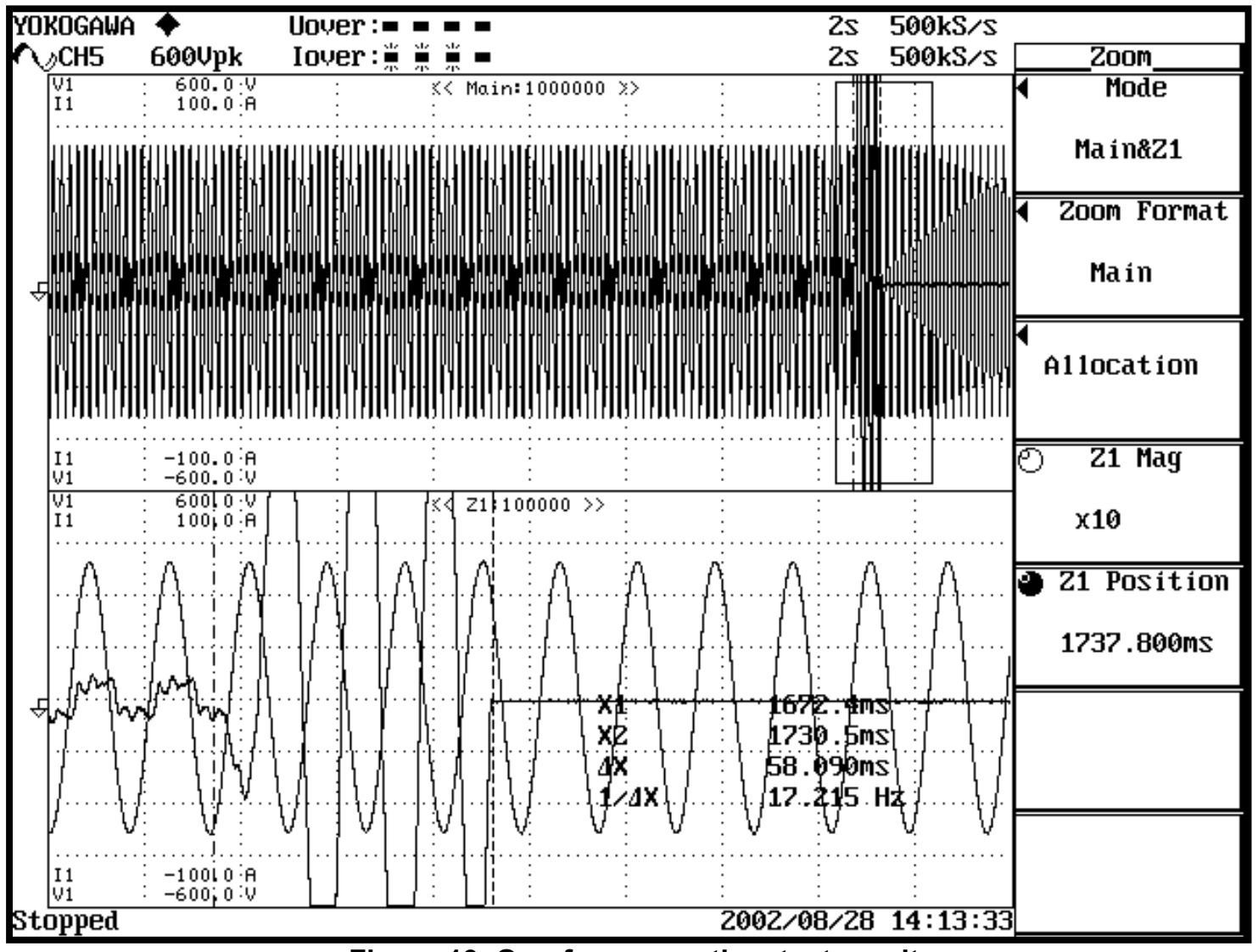

Figure 13. Overfrequency time test results 


\subsubsection{Underfrequency Magnitude}

For the underfrequency tests, the grid simulators supplied $50 \mathrm{~kW}$ of a $60-\mathrm{kW}$ utility load, and the diesel powered a $20-\mathrm{kW}$ local load and exported $10 \mathrm{~kW}$ back to the utility. Both a slow and a fast underfrequency requirement are specified in IEEE 1547 Section 4.2.4 Table 2 (Appendix A) for DG greater than $30 \mathrm{~kW}$. Under $57 \mathrm{~Hz}$, the DG must disconnect in less than $0.16 \mathrm{~s}$, but between 57 and $59.8 \mathrm{~Hz}$, the clearing time is adjustable up to $300 \mathrm{~s}$. For the slow underfrequency test, $59.3 \mathrm{~Hz}$ was used for the ASCO trip setting at a clearing time delay of $1.7 \mathrm{~s}$. The slow step function around $59.3 \mathrm{~Hz}$ is shown in Figure 14. The results using the Yokogawa power analyzer for Trial 4 are displayed in Figure 15. The dashed vertical lines measure the period of the red phase just before the trip signal.

Table 4. Underfrequency Magnitude

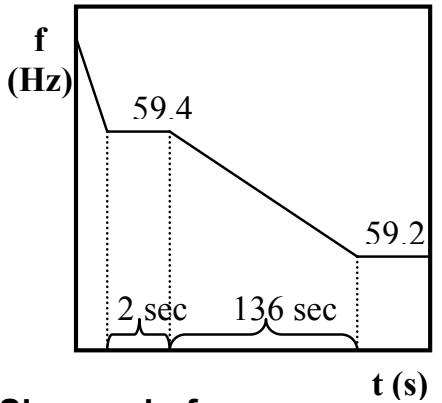

\begin{tabular}{cr}
\hline \multicolumn{2}{c}{ Underfrequency Magnitude } \\
Trial Number & Trip Frequency \\
\cline { 2 - 2 } 1 & 59.301 \\
2 & 59.311 \\
3 & 59.298 \\
4 & 59.312 \\
5 & 59.284 \\
Average & $\mathbf{5 9 . 3 0 1}$ \\
Setting & $\mathbf{5 9 . 3}$ \\
\hline
\end{tabular}

Figure 14. Slow underfrequency ramp function

59.3

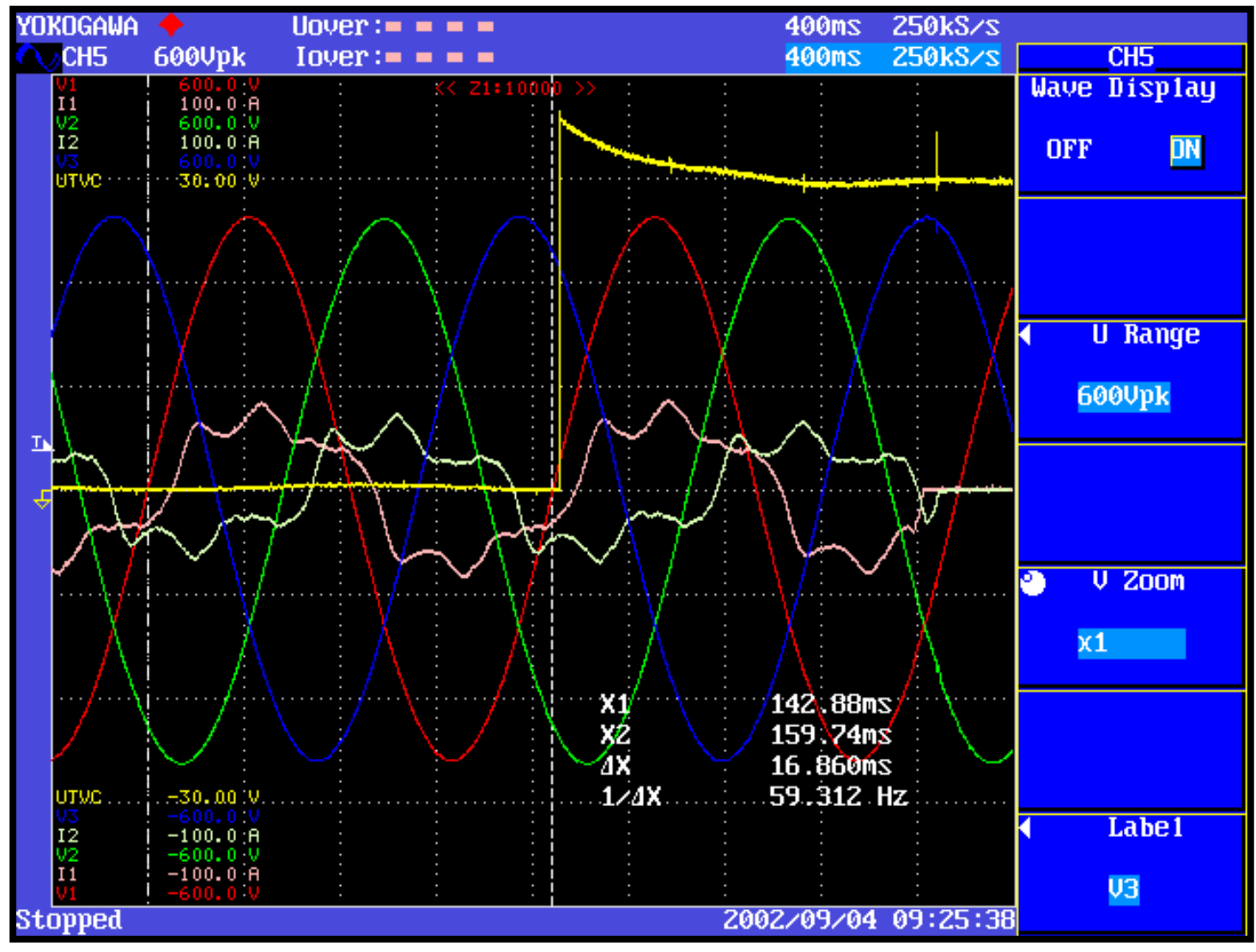

Figure 15. Underfrequency magnitude test results 


\subsubsection{Underfrequency Time}

Again, $99.5 \%$ of $\mathrm{P}_{\mathrm{T}}$ was used for $\mathrm{P}_{\mathrm{U}}$ instead of the $90 \%$ called for in the $\mathrm{P} 1547.1$ procedures to avoid tripping on other protective functions. The grid simulator frequency step function is shown in Figure 16, and Figure 17 illustrates the trip time from Trial 3.

Table 5. Underfrequency Time

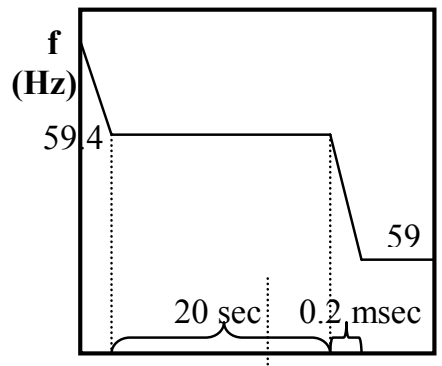

t (s)

\begin{tabular}{|c|c|}
\hline \multicolumn{2}{|c|}{ Underfrequency Time } \\
\hline Trial Number & Trip Time (s) \\
\hline 1 & 1.58 \\
\hline 2 & 1.48 \\
\hline 3 & 1.58 \\
\hline 4 & 1.57 \\
\hline 5 & 1.54 \\
\hline Average & 1.55 \\
\hline Required & 1.70 \\
\hline
\end{tabular}

Figure 16. Underfrequency step function



Figure 17. Underfrequency time test results 


\subsubsection{Fast Underfrequency Magnitude}

Even though the ASCO internal time delay setting for this parameter is instantaneous, using the 0.5 $\mathrm{s}$ inherent system delay for the value of $\mathrm{z}$ in Equation 2 to calculate the slope, $\mathrm{m}$, gives a reasonable value of $0.1 \mathrm{~Hz} / 20 \mathrm{~s}$. Again, Figure 18 is the frequency ramp function used, and Figure 19 shows the frequency just before the breaker was tripped.

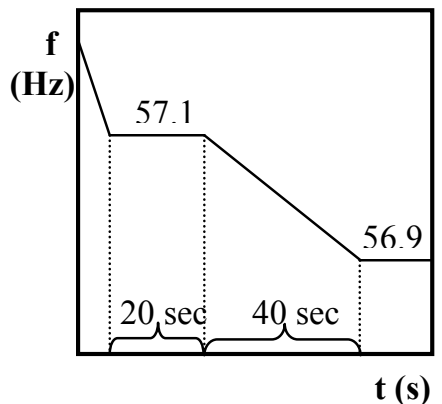

Figure 18. Fast underfrequency ramp

Table 6. Fast Underfrequency Magnitude

Fast Underfrequency Magnitude

Trial Number

$$
1
$$

2

3

4

5

Average

Setting

\begin{tabular}{c} 
Trip Frequency \\
\hline 57.000 \\
56.987 \\
57.000 \\
57.000 \\
56.987
\end{tabular}

56.995

57.0

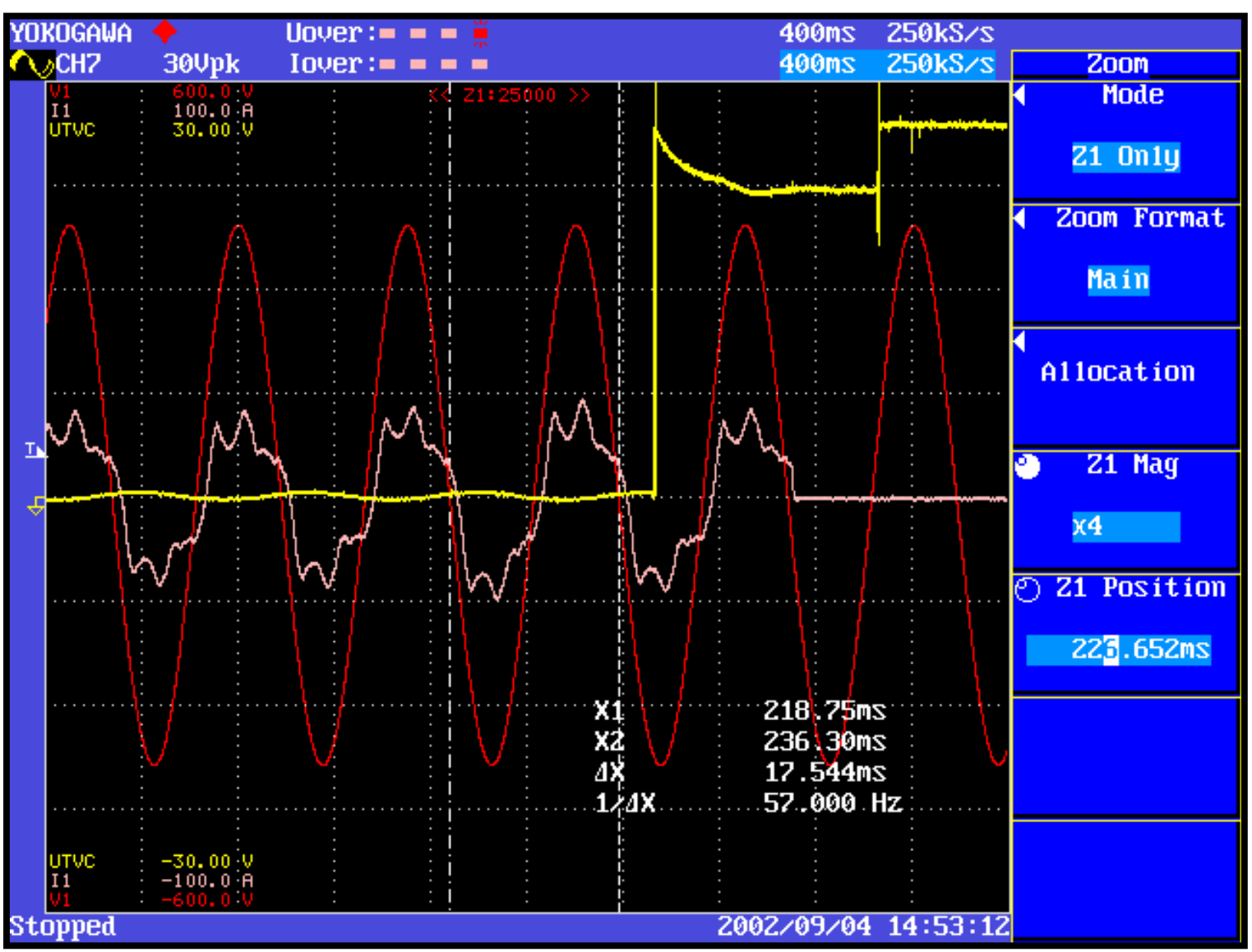

Figure 19. Fast underfrequency magnitude results 


\subsubsection{Fast Underfrequency Time}

The final part of the abnormal frequency testing was nearly identical to the slow underfrequency time test but at a lower frequency, as shown in Figure 20, and with a faster disconnect time, as shown in Figure 21. Again, the ASCO disconnected the generator well before the required $160 \mathrm{~ms}$.

Table 7. Fast Underfrequency Time

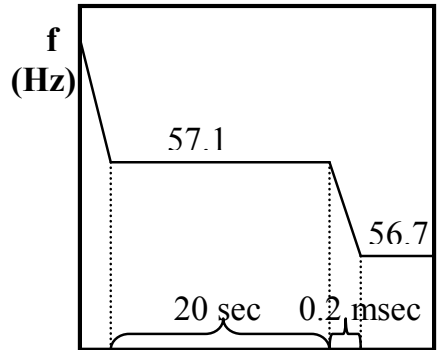

t (s)

Figure 20. Fast underfrequency step
Fast Underfrequency Time

Trial Number

1

2

3

4

5

Average

46.84

Required

160.0

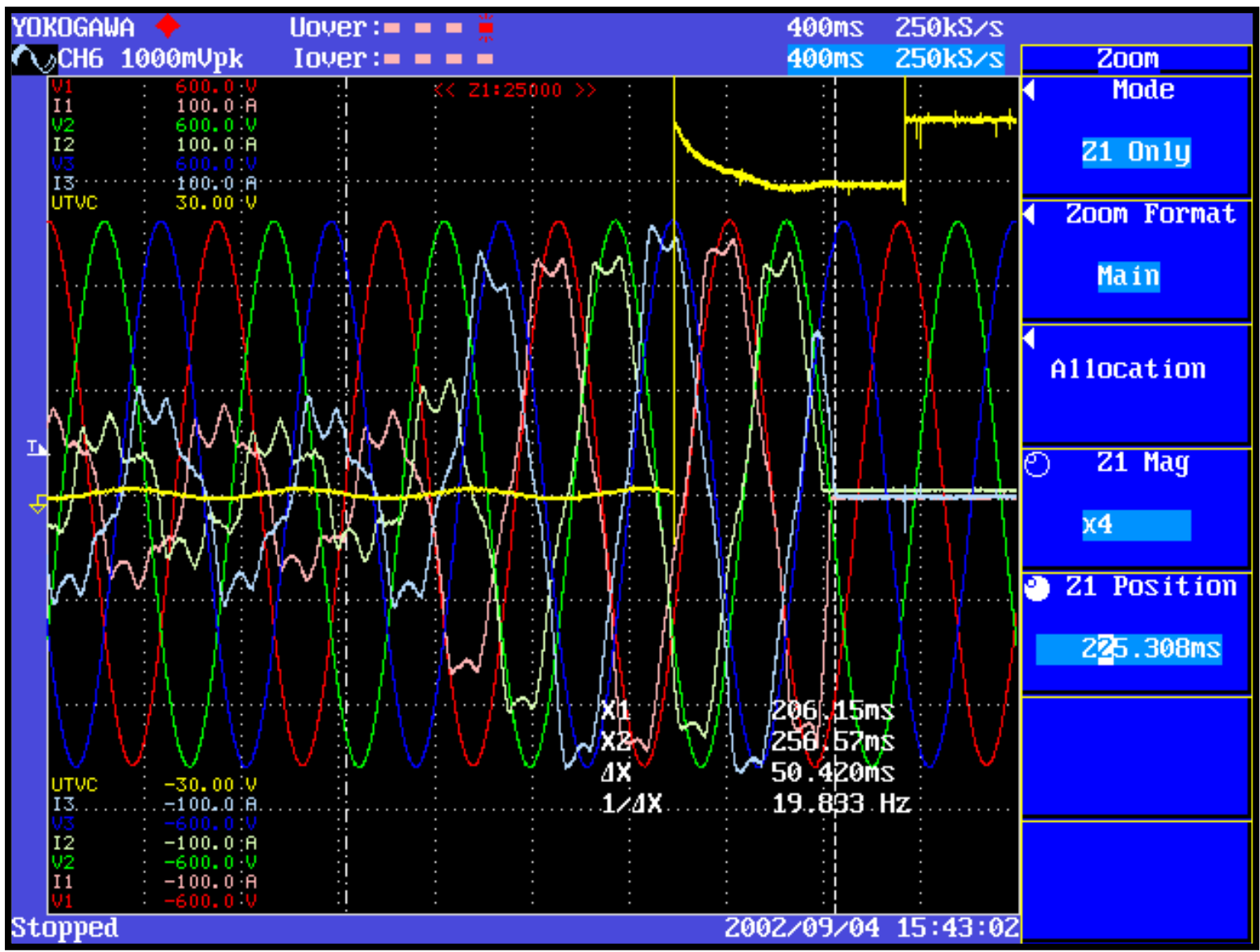

Figure 21. Fast underfrequency time test results 


\subsection{Voltage Test Results}

\subsubsection{General Information}

The general conditions established for these tests were identical to those for frequency testing:

- The ASCO unit paralleled the $125-\mathrm{kW}$ diesel to the simulated utility grid and closed all breakers.

- First, a $30-\mathrm{kW}$ load was added to the utility bus $\left(\mathrm{P}_{\text {util }}\right)$, and then another $30 \mathrm{~kW}$ was placed on the common bus, interconnected with both the utility and the DG through the ASCO breakers (shown as "emergency load" in Figure 5). The grid simulators initially supplied all of both loads.

- The ASCO then controlled the diesel generator power export $\left(\mathrm{P}_{\text {export }}\right)$ to assume the entire $30-\mathrm{kW}$ local load and to load share with the utility, exporting an additional $10 \mathrm{~kW}$.

Under these conditions, the ASCO controlled the genset excitation to maintain power factor. By maintaining the grid simulator rate of voltage change below the time response of the diesel exciter, power factor could be held constant while bus voltage was decreased or increased.

For the voltage testing, the most consistent results were observed with a non-unity power factor setting for the diesel generator. A power factor of 0.9 was used for these tests. This also provided a reactive load sink to limit generator reverse VARs.

Also, the narrow range of the diesel voltage regulator would not allow testing at the voltage levels required by the IEEE 1547 and Draft P1547.1 standards. 1547 has no disconnect or testing requirements for voltages ranging between $89 \%$ and $109 \%$ of normal. The voltage levels closest to nominal values that IEEE 1547 requires to be tested are $88 \%$ of the nominal $480 \mathrm{~V}(422.4 \mathrm{~V})$ for undervoltage and 110\% (528 V) for overvoltage (see Appendix A, Table 1). These levels are for the slow response testing; the fast response goes all the way to less than $50 \%$ or greater than $120 \%$, but even the slow response minimum values were unattainable. Voltage regulator settings prohibited the diesel generator from operating outside a range of only about $\pm 6 \%$ of nominal voltage ( $450 \mathrm{~V}$ and $505 \mathrm{~V})$. To work around this restriction, set points within the range of the diesel were tested. This was done by manually relaxing the voltage set points programmed into the ASCO controller to only $\pm 25-30 \mathrm{~V}$ around the nominal $480 \mathrm{~V}$. Testing over the full voltage range might have been possible after adjusting the diesel voltage regulator settings but could risk damaging the generator.

For all of the voltage tests, the utility supplied a $30-\mathrm{kW}$ utility load, and the diesel fed a $30-\mathrm{kW}$ local load and exported $10 \mathrm{~kW}$ back to the utility load. Peak voltage values at the trip were determined using the "measure" command on the Yokagawa scope. This command gave peak lineto-neutral voltage, which was converted to RMS phase-to-phase voltage by multiplying by $\sqrt{\frac{3}{2}}$. 


\subsubsection{Overvoltage Magnitude}

With the ASCO overvoltage limit set to $504 \mathrm{~V}$ (only $105 \%$ nominal voltage because the $110 \%$ $120 \%$ specified in IEEE 1547 was unreachable without tripping other protective functions), the ramp function shown in Figure 20 gave the expected average trip magnitude of $504 \mathrm{~V}$. Figure 23 shows the line-to-neutral voltage for Trial 5 as the Y1 value of the dotted horizontal line.

Multiplying by $\sqrt{\frac{3}{2}}$ converts back to the $504 \mathrm{~V}$, RMS phase-to-phase voltage given in Table 8 .

\section{Table 8. Overvoltage Magnitude}

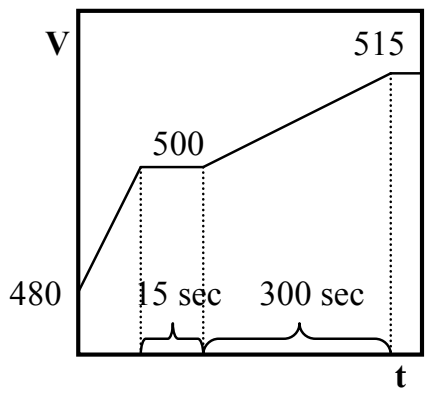

\begin{tabular}{cr}
\hline \multicolumn{2}{c}{ Overvoltage Magnitude } \\
Trial Number & \begin{tabular}{c} 
Trip Voltage \\
\cline { 2 - 2 } 1
\end{tabular} \\
2 & 504.300 \\
3 & 502.500 \\
4 & 504.700 \\
5 & 504.600 \\
Average & 504.150 \\
Setting & $\mathbf{5 0 4 . 0 5 0}$ \\
\hline
\end{tabular}

Figure 22. Overvoltage ramp function

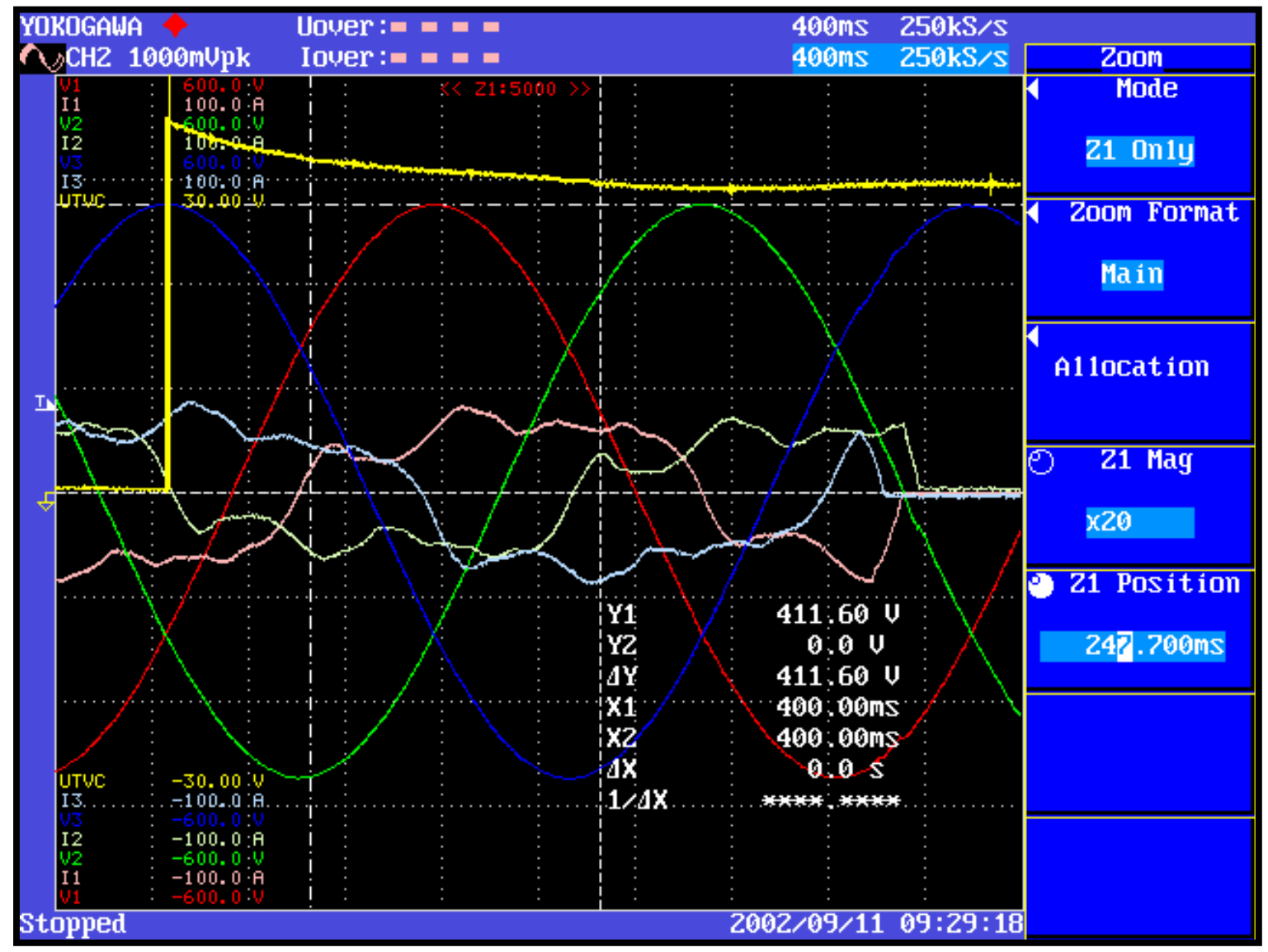

Figure 23. Overvoltage magnitude test results 


\subsubsection{Overvoltage Time}

After determining the 504-V overvoltage trip point, the time test found the delay between exceeding that trip point and disconnecting the DG. Figure 24 shows the voltage function executed by the grid simulator. Figure 25 displays the results from Trial 5, with the lower half of the figure zoomed in at the voltage jump from $500 \mathrm{~V}$ to $510 \mathrm{~V}$. Even though the voltage setting was abnormally low, the ASCO unit isolated the diesel in less than half of the 1-s disconnect time required by IEEE 1547 for $110 \%-120 \%$ of nominal voltage (Appendix A).

Table 9. Overvoltage Time

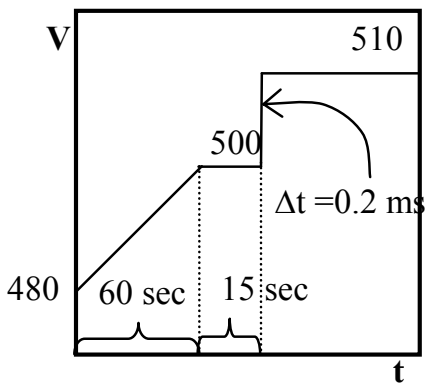

\begin{tabular}{cc}
\hline \multicolumn{2}{c}{ Overvoltage Time } \\
Trial Number & Trip Time (s) \\
\cline { 2 - 2 } 1 & 0.436 \\
2 & 0.428 \\
3 & 0.378 \\
4 & 0.396 \\
5 & 0.468 \\
Average & $\mathbf{0 . 4 2 1}$ \\
Required & $\mathbf{1 . 0 0}$ \\
\hline
\end{tabular}

Figure 24. Overvoltage step function

Required

1.00

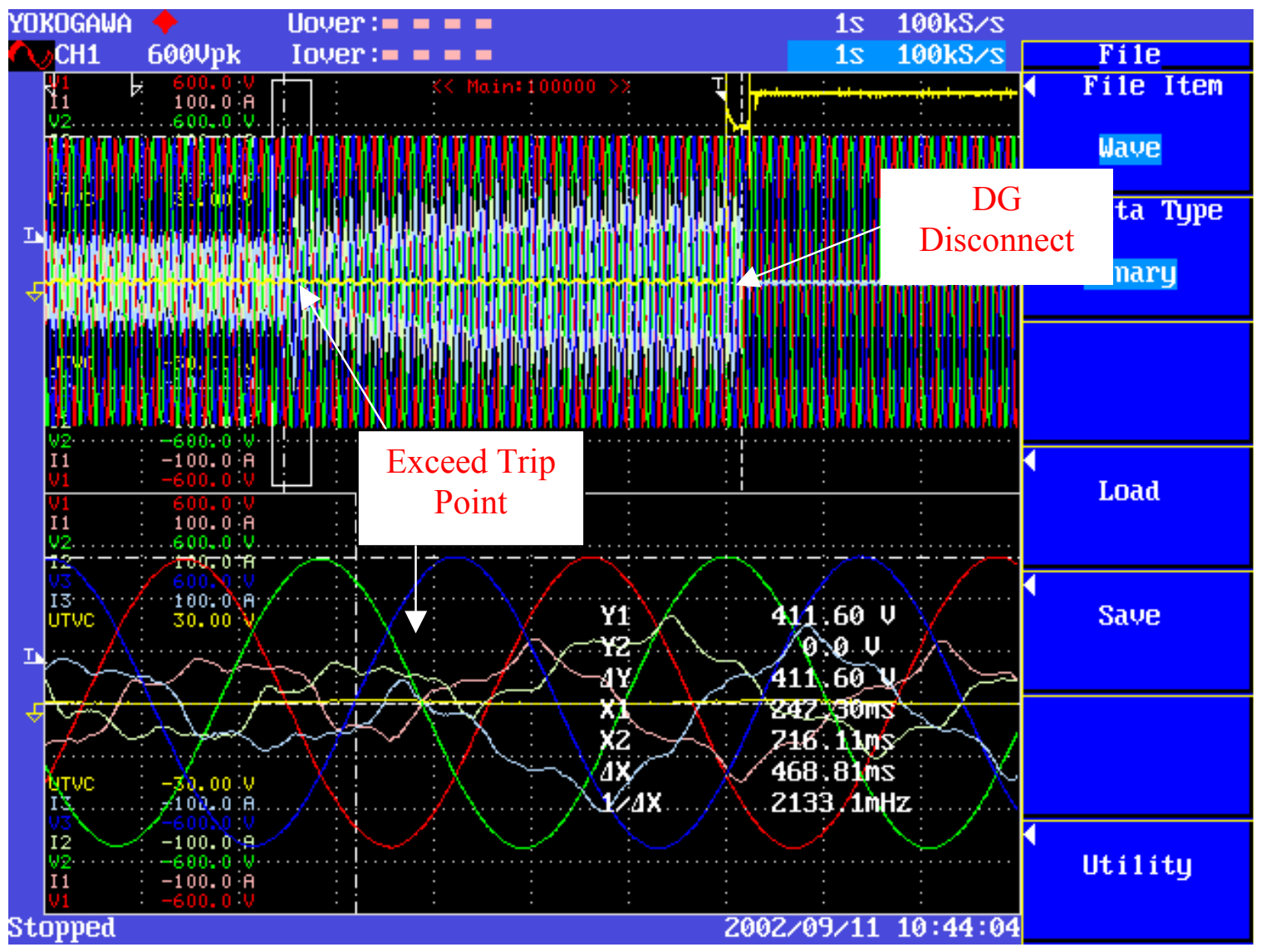

Figure 25. Overvoltage time test results 


\subsubsection{Fast Overvoltage Magnitude}

The horizontal dotted line Y1 in Figure 27 measures the peak voltage of the blue phase on the cycle just before the generator tripped. The average trip magnitude was found to be about $501.4 \mathrm{~V}$ for the fast overfrequency test. As with slow overfrequency, the overvoltage set point was still set at $504 \mathrm{~V}$, but the time delay was now only $0.16 \mathrm{~s}$.

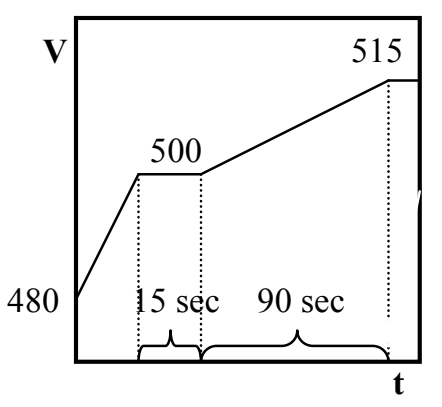

Figure 26. Fast overvoltage ramp function
Table 10. Fast Overvoltage Magnitude

\begin{tabular}{cc}
\multicolumn{2}{c}{ Fast Overvoltage Magnitude } \\
Trial Number & Trip Voltage \\
\cline { 2 - 2 } 1.0 & 501.7 \\
2.0 & 499.8 \\
3.0 & 501.7 \\
4.0 & 501.7 \\
5.0 & 502.2
\end{tabular}

Average

501.4

Setting

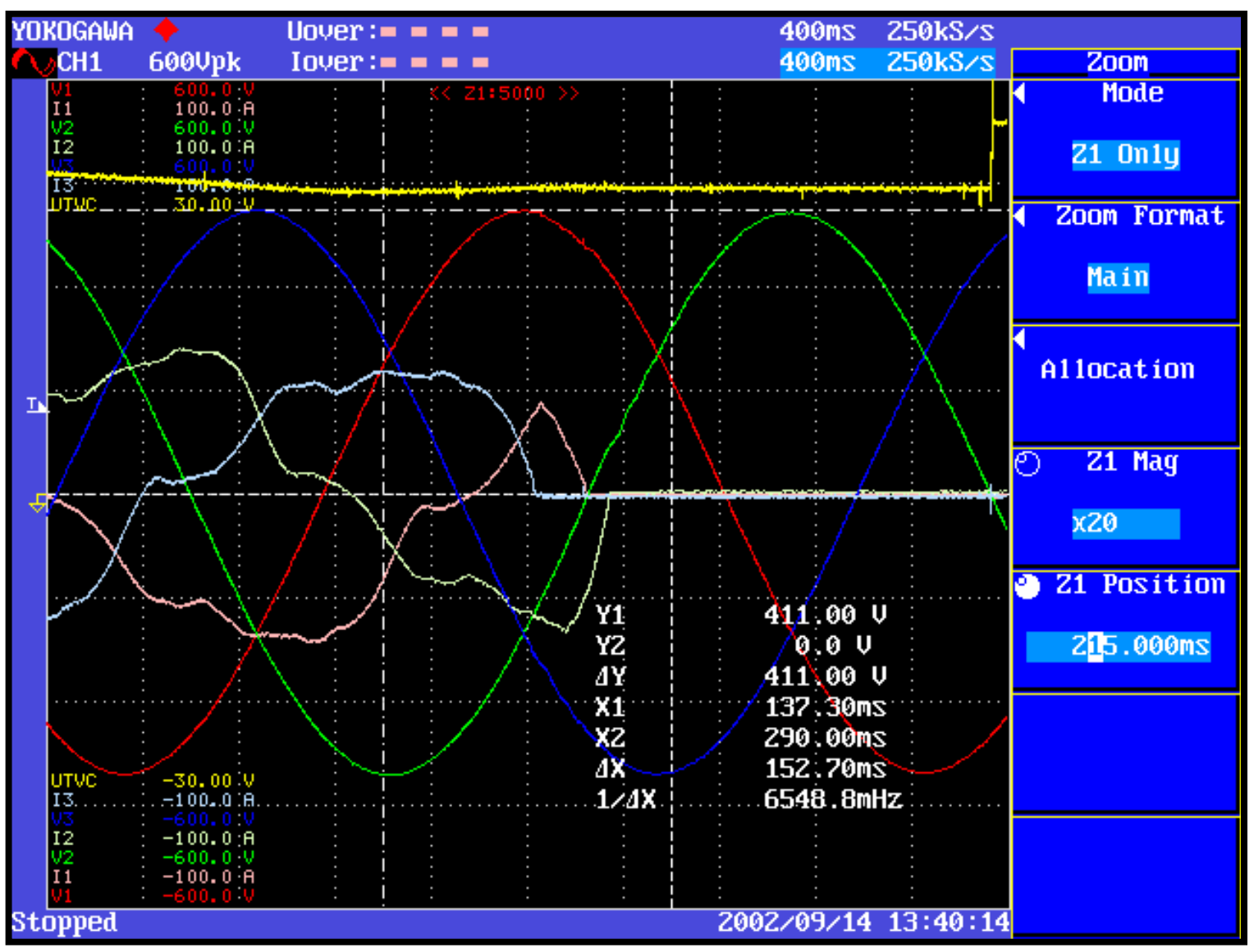

Figure 27. Fast overvoltage magnitude test results 


\subsubsection{Fast Overvoltage Time}

The ASCO unit had no trouble disconnecting within the $160 \mathrm{~ms}$ required for the faster response, even with the artificially low overvoltage. Every trial disconnected in fewer than $50 \mathrm{~ms}$. Again, Figure 28 shows the voltage step function, and Figure 29 measures the trip time.

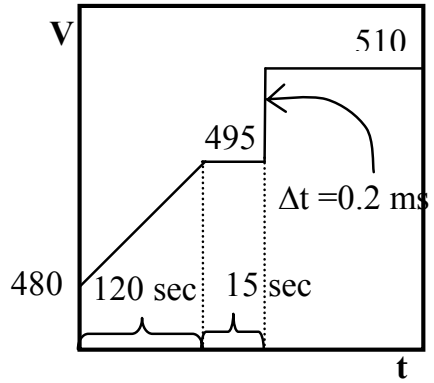

Figure 28. Fast overvoltage step function

\section{Table 11. Fast Overvoltage Time}

Fast Overvoltage Time

Trial Number Trip Time (ms)

$\begin{array}{ll}1.0 & 40.2 \\ 2.0 & 41.4 \\ 3.0 & 36.5 \\ 4.0 & 46.9 \\ 5.0 & 48.1\end{array}$

Average

42.6

Required

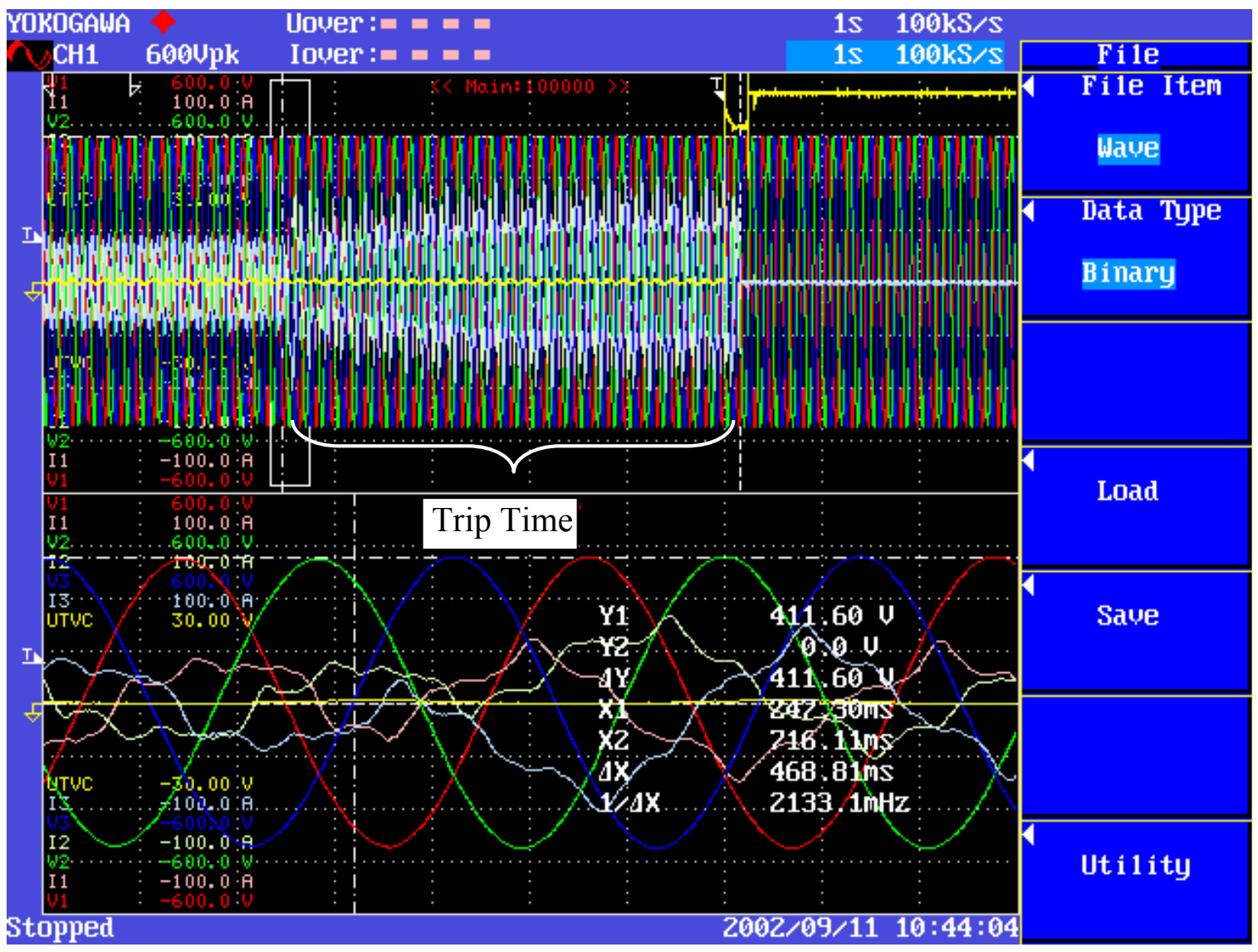

Figure 29. Fast overvoltage time test results 


\subsubsection{Undervoltage Magnitude}

Again, for undervoltage as for overvoltage, settings had to be relaxed to allow for testing. In place of the $50 \%-88 \%$ of nominal voltage $(240-422.4 \mathrm{~V})$, only about $93 \%(446 \mathrm{~V})$ could be reached before tripping on "reverse excess VARs." The undervoltage trip has a 1.7-s time delay setting, within the 2-s IEEE requirement. The ASCO unit tripped undervoltage at $458.1 \mathrm{~V}$ when set to trip at $456 \mathrm{~V}$.

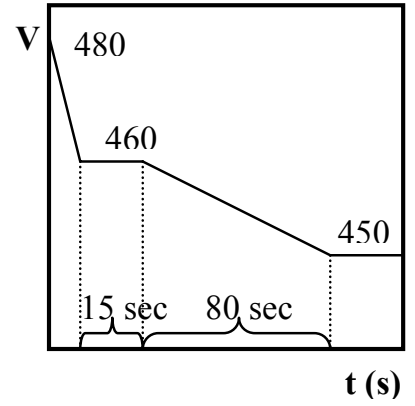

Figure 30. Undervoltage ramp function
Table 12. Undervoltage Magnitude

\begin{tabular}{|c|c|}
\hline \multicolumn{2}{|c|}{ Undervoltage Magnitude } \\
\hline Trial Number & Trip Voltage \\
\hline 1.0 & 459.8 \\
\hline 2.0 & 453.4 \\
\hline 3.0 & 458.7 \\
\hline 4.0 & 458.7 \\
\hline 5.0 & 459.8 \\
\hline
\end{tabular}

Average

458.1

Setting

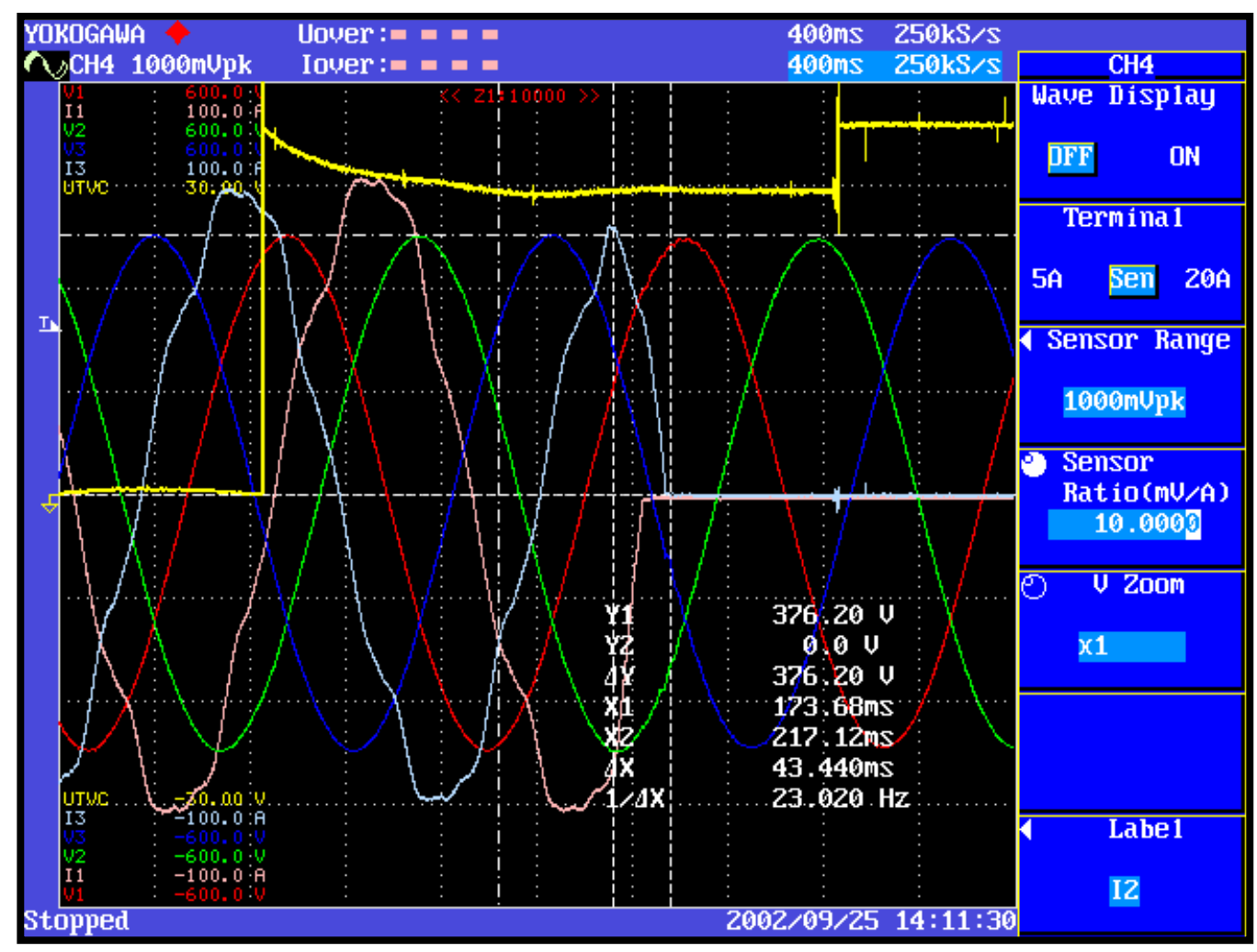

Figure 31. Undervoltage magnitude test results 


\subsubsection{Undervoltage Time}

Quickly stepping below the 458.1-V trip magnitude as shown in Figure 33, the average trip time was found to be $1.91 \mathrm{~s}$ with the ASCO undervoltage time delay set to $2 \mathrm{~s}$. Figure 33 shows the current steadily rising from the sudden voltage increase until the ASCO unit trips. The lower portion of the graph is an enlarged view of current dropping to zero when the ASCO unit disconnects the diesel.

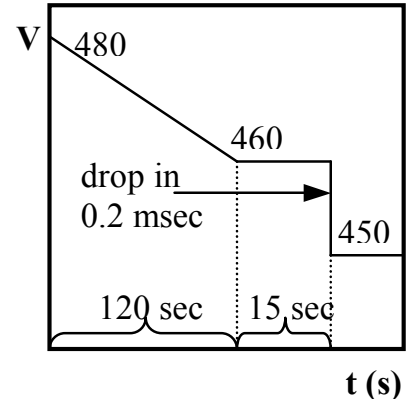

Figure 32. Undervoltage step function
Table 13. Undervoltage Time

\begin{tabular}{ccc}
\hline \multicolumn{2}{c}{ Undervoltage Time } \\
Trial Number & Trip Time (s) \\
\cline { 2 - 2 } 1.0 & 1.92 & \\
2.0 & 1.92 & \\
3.0 & 1.88 & \\
4.0 & 1.93 & \\
5.0 & 1.88 & \\
Average & & $\mathbf{1 . 9 1}$ \\
Required & & $\mathbf{2 . 0 0}$ \\
\hline
\end{tabular}

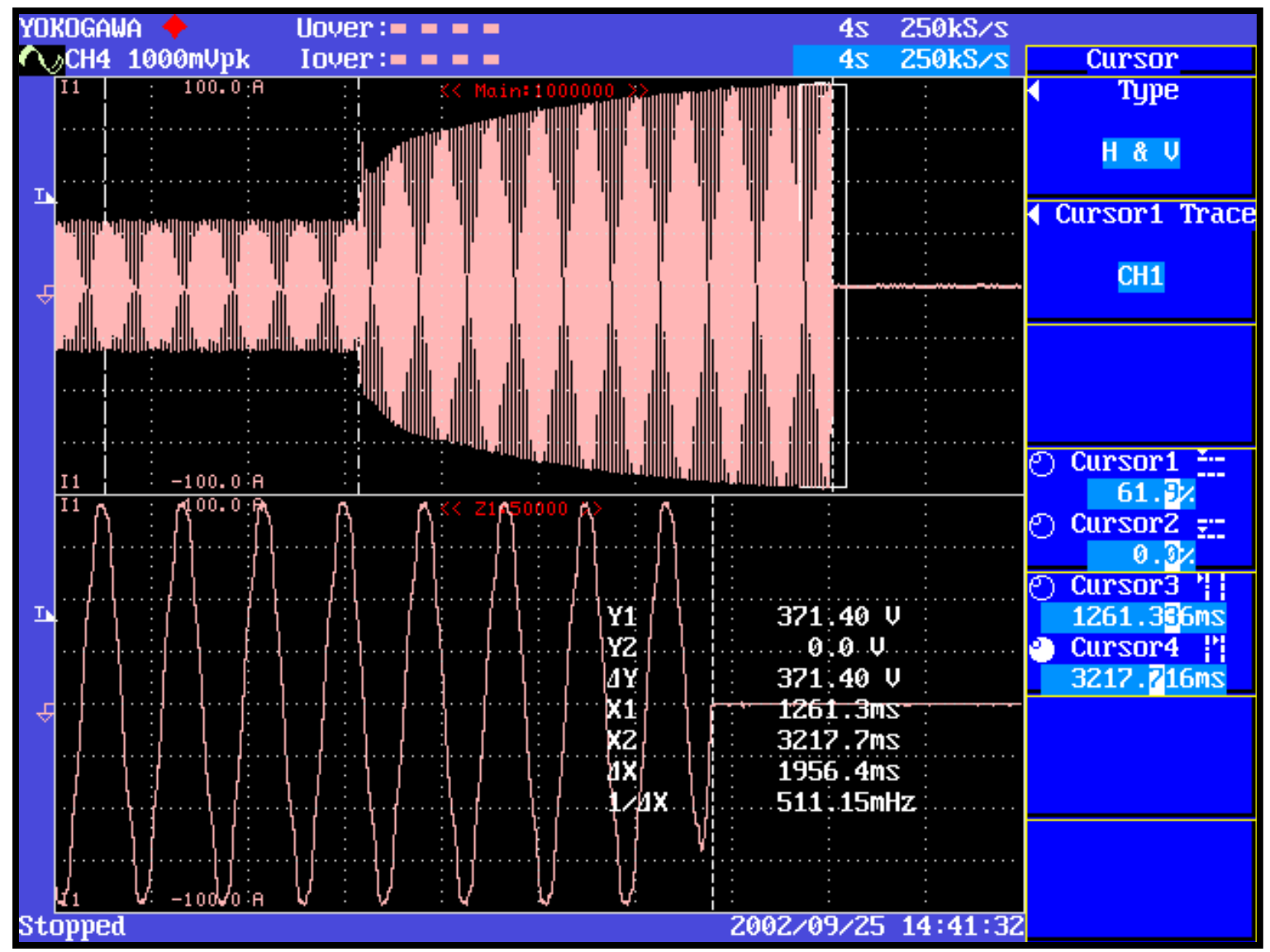

Figure 33. Undervoltage time test results 


\subsubsection{Fast Undervoltage Magnitude}

The final abnormal voltage or frequency test was fast undervoltage. For this test, $446 \mathrm{~V}$ was used as the trip voltage. However, the time setting was again $0.16 \mathrm{~s}$, as with the fast overvoltage tests. During the gradual $460 \mathrm{~V}$ to $445 \mathrm{~V}$ grid simulator ramp given in Figure 34, the trip magnitude was found to be $453.1 \mathrm{~V}$. Figure 35 shows the peak line voltage of $372 \mathrm{~V}$ for Trial 2.

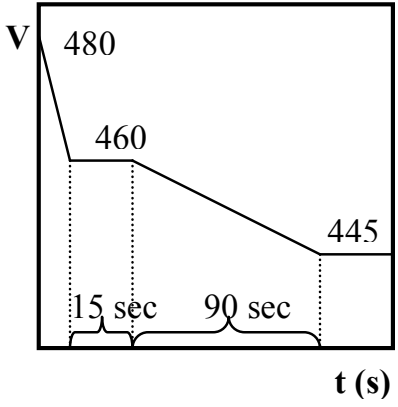

Figure 34. Fast undervoltage ramp function
Table 14. Fast Undervoltage Magnitude

\begin{tabular}{cc} 
Fast Undervoltage Magnitude \\
Trial Number & \begin{tabular}{c} 
Trip Voltage \\
\cline { 2 - 2 } 1.0
\end{tabular} \\
2.0 & 451.9 \\
3.0 & 455.6 \\
4.0 & 454.9 \\
5.0 & 454.1 \\
Average & 449.0 \\
Setting & $\mathbf{4 5 3 . 1}$ \\
\hline
\end{tabular}

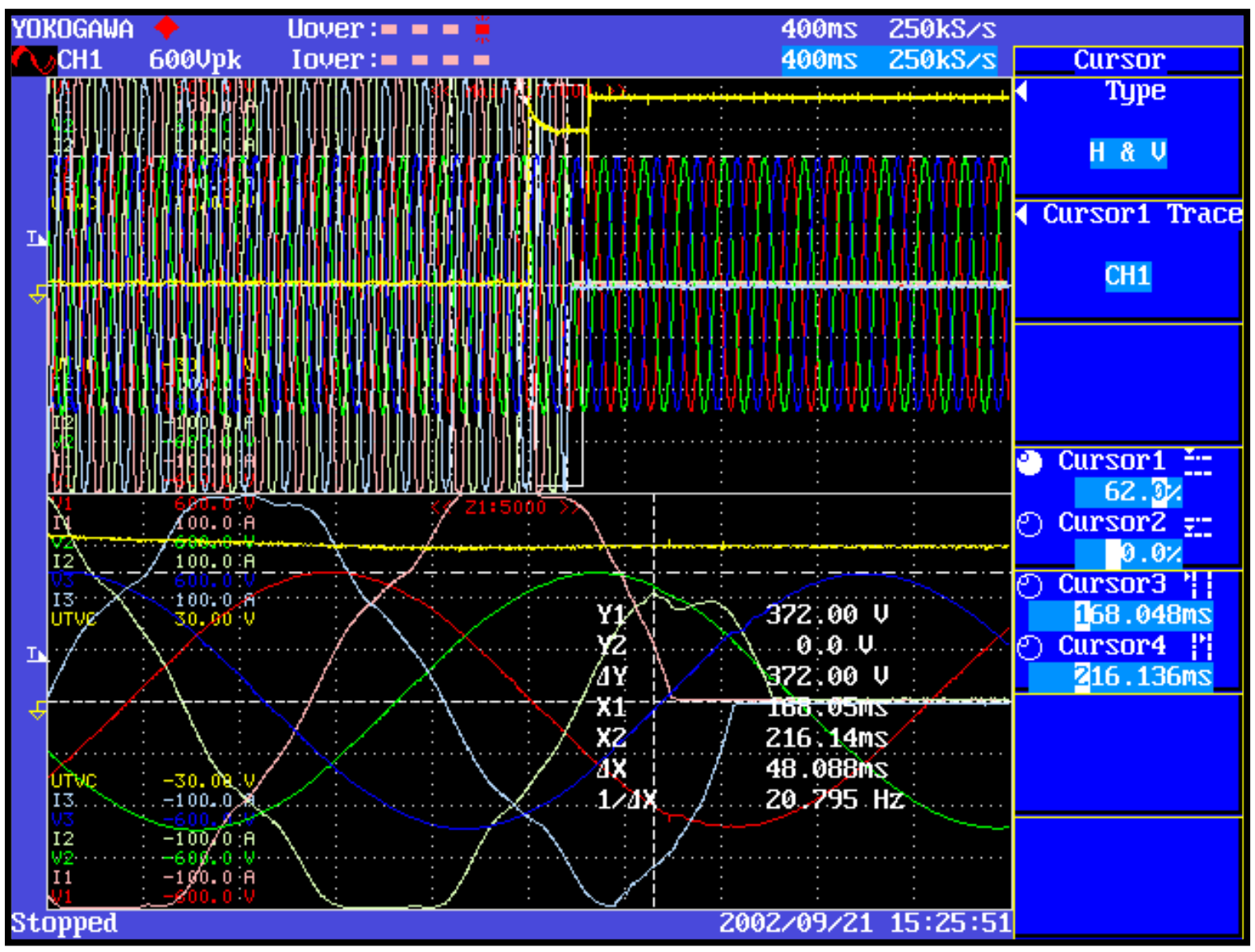

Figure 35. Fast undervoltage magnitude test results 


\subsubsection{Fast Undervoltage Time}

Finally, testing showed that the ASCO unit took about $57 \mathrm{~ms}$ to trip after the grid stepped below $453.1 \mathrm{~V}$. This value was well under the 160 -ms IEEE 1547 requirement. The time between the sharp current increase from the sudden drop in voltage to when the current drops to zeros with the ASCO trip is displayed in Figure 37 for Trial 4.

Table 15. Fast Undervoltage Time

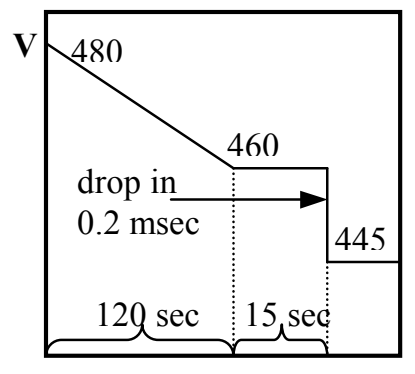

$t(s)$

Figure 36. Fast undervoltage step function

\begin{tabular}{|c|c|}
\hline \multicolumn{2}{|c|}{ Fast Undervoltage Time } \\
\hline Trial Number & Trip Time (ms) \\
\hline 1.0 & 54.5 \\
\hline 2.0 & 55.0 \\
\hline 3.0 & 57.2 \\
\hline 4.0 & 74.9 \\
\hline 5.0 & 43.4 \\
\hline Average & 57. \\
\hline Required & 160. \\
\hline
\end{tabular}

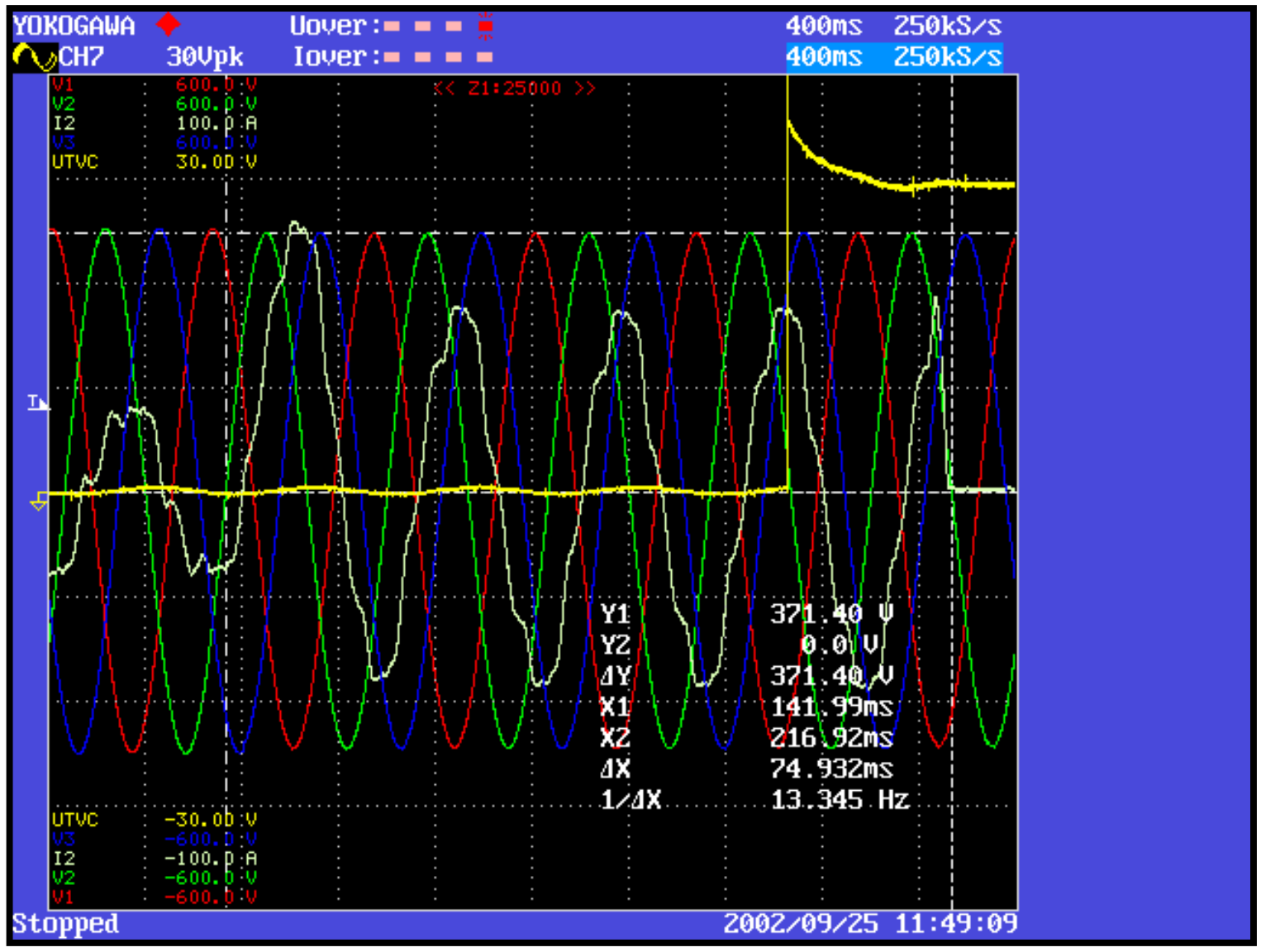

Figure 37. Fast undervoltage time test results 


\section{$6 \quad$ Anti-Islanding Testing}

\subsection{General Information}

Islanding is when a distributed generator continues to supply power to a portion of the EPS when that portion of the grid is de-energized. Both power utilities and regulatory requirements demand the prevention of unintentional islands to ensure the safety of utility personnel and the integrity of the power system. Ideally, whatever event caused the local section of the grid to shut down should also trip the distributed generator protective function, or the sudden increase in load from the loss of local grid power should disrupt system conditions enough to trip the distributed generator.

Still, a laboratory environment can simulate the worst-case scenario of matching the generator output to the load, adding capacitive and inductive load for a quality factor (Q) of 1.8, and quietly dropping out the utility power without disturbing system parameters. Previous islanding testing used $\mathrm{Q}=2.5$; updated UL and IEEE standards now use $\mathrm{Q}=1.8 . \mathrm{Q}=2.5$ corresponds to a load power factor of 0.37 . $Q=1.8$ corresponds to a load power factor of 0.55 . $Q=2.5$ originated with most difficult condition for inverter anti-islanding algorithm to work. Utility circuits typically operate above $0.75 \mathrm{pf}$ in steady-state conditions; therefore, $\mathrm{Q}=1.8(\mathrm{pf}=0.55)$ is below the load power factor that the DR is expected to be islanded with. Although unlikely in the field, successful worst-case testing demonstrates that the device can identify islands and quickly disconnect in most any situation.

Passive anti-islanding schemes measure system voltage and frequency to detect and disconnect should an island occur. These strategies can work well as long as there is a variation in voltage or frequency great enough to detect the island when it is initiated. With the generator and load matched, the loss of the grid may not instantly produce significant changes, especially if there is reactive load to help maintain the system voltage and frequency. Active anti-islanding schemes periodically try to push the grid voltage or frequency out of bounds. If the grid is down, then the generator can dictate the values and, after exceeding a threshold, disconnect the generator. With the utility power system operational, the relatively small distributed generator cannot significantly influence the system voltage or frequency. 


\subsection{Anti-Islanding Test Setup}

The anti-islanding tests were performed within the same system as abnormal voltage and frequency, shown in Figure 38.

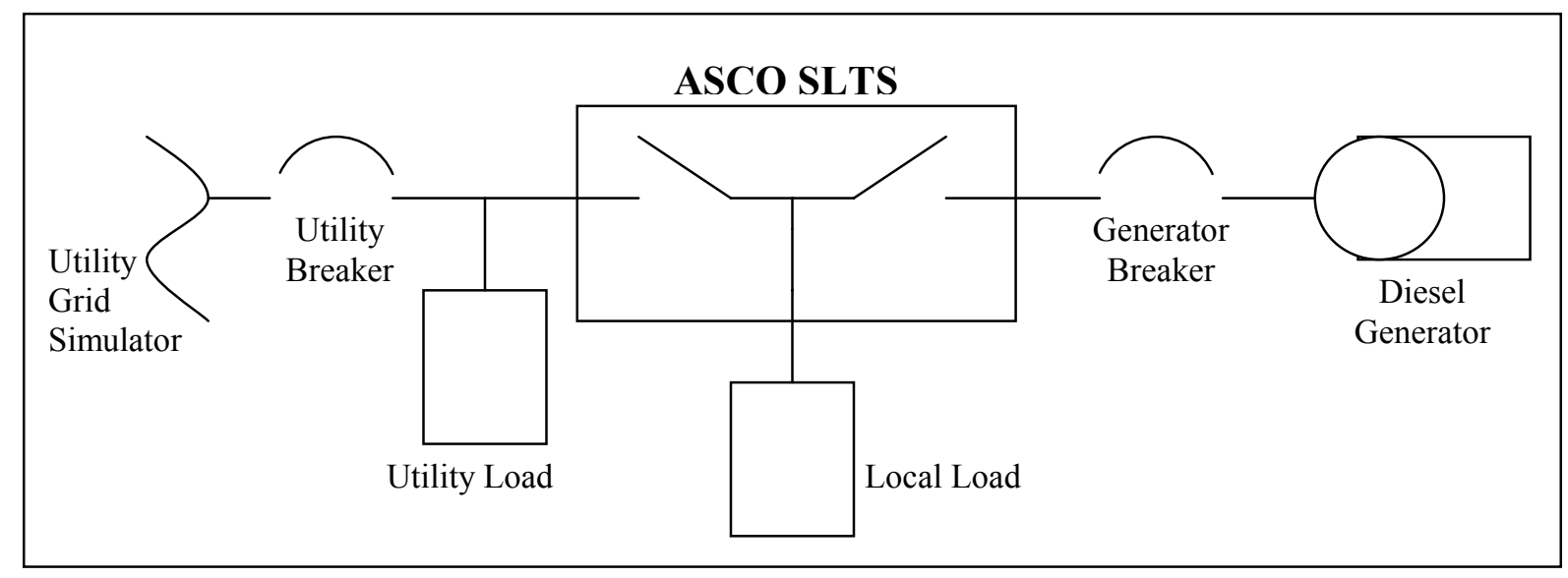

Figure 38. Anti-islanding test setup

Placement of the load, whether entirely at the utility load or the local load, did not significantly influence the ASCO detection times, which averaged 17.12 or $17.14 \mathrm{~s}$ without the anti-islanding function. Therefore, all the later tests used only the local load to better simulate a generator interconnected with the grid but completely supplying only a local load. When the grid becomes de-energized, the local system conditions do not immediately change, but the ASCO must still recognize the island formation and disconnect the generator within $2 \mathrm{~s}$. To further challenge the ASCO unit, inductive and capacitive elements were added to the local load to create a 1.8 load quality factor to help maintain the local power characteristics after the loss of the utility.

Tests were conducted to investigate the effects of the diesel power factor setting, the generator load level, and the anti-islanding deadband setting on the ASCO trip time. Loads at $25 \%(30 \mathrm{~kW})$, $50 \%(63 \mathrm{~kW})$, and near $100 \%(100 \mathrm{~kW})$ were all tested at unity load power factor with matching inductive and capacitive loads to create a 1.8 quality factor. Testing was conducted with the diesel power factor setting at unity, 0.9 lagging, and, in some cases, 0.95 lagging. The deadband setting of the anti-islanding function is an adjustable sensitivity range. The anti-islanding software attempts to disrupt the grid, and with no energized grid to maintain voltage and frequency, the ASCO can force values beyond the set deadband cushion before disconnecting the generator. Deadband settings of $0.1,0.05$, and 0.03 were used in tests.

The testing procedure for anti-islanding was similar to abnormal voltage and frequency. Initially, with the distributed generator disconnected, the grid simulator would supply a local load $10 \mathrm{~kW}$ or $20 \mathrm{~kW}$ greater than the desired diesel output to avoid backfeeding the grid simulators when ramping up the diesel. The diesel would then be paralleled and would supply most of the local load; the simulated utility still contributed $10-20 \mathrm{~kW}$. Next, matched inductive and capacitive loads were added to achieve a quality factor of about 1.8. The capacitive load was then slightly increased to reach the desired power factor (accounting for transformer and other stray system inductances), and the resistive load setting was slowly reduced to match the diesel output with the load and eliminate current from the utility. Finally, the utility breaker external to the ASCO unit 
was tripped to island the distributed generator and record the disconnect time. Test results are discussed in the following section.

\subsection{Anti-Islanding Test Results}

Under the matched, undisturbed conditions of the laboratory setup, the ASCO unit did not identify the island and disconnect in less than $2 \mathrm{~s}$ with the anti-islanding function disabled. In some cases, the island lasted longer than the 3-min maximum observation time.

Regardless of diesel power factor setting or generator loading, it appears that with the correct deadband setting, the anti-islanding software can always recognize an island and clear the generator in less than $2 \mathrm{~s}$. At the 0.1 deadband setting, islanding detection was sporadic. However, the ASCO unit consistently detected and discontinued islands with the deadband at 0.05 . Reducing the deadband to 0.03 seemed generally to be unnecessary. It was unclear whether a 0.03 deadband setting offered any advantage over the 0.05 setting, and the greater sensitivity of 0.03 would increase the risk of nuisance tripping.

Figure 39 shows clearing times for loads and deadband settings. The diesel is set to generate at a 0.9 power factor while carrying equal inductive and capacitive loads for a unity load power factor at a 1.8 quality factor.

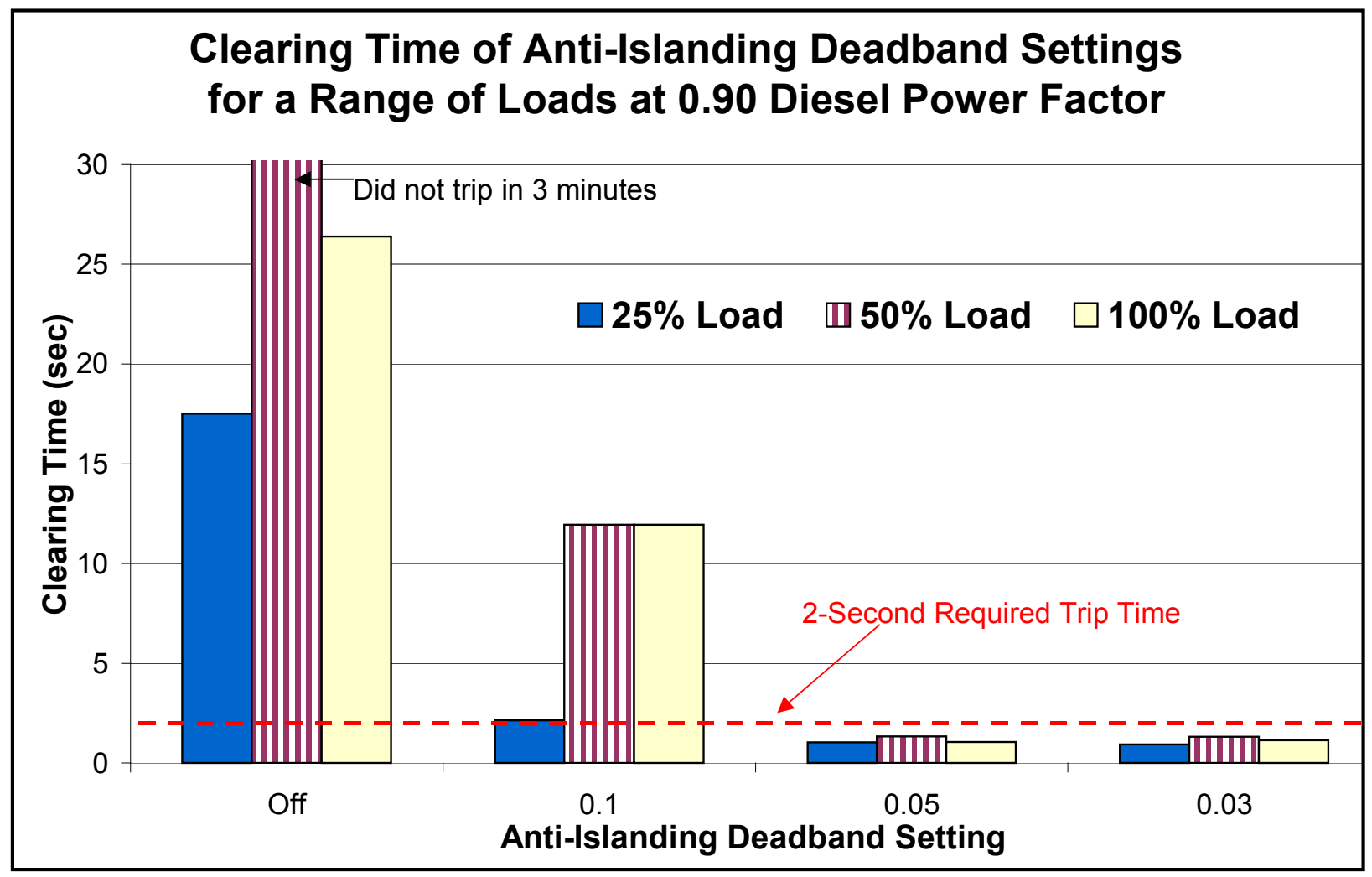

Figure 39. Anti-islanding clearing times comparison 
Because the clearing time both increased and decreased based on changing power factor, the effect of the diesel power factor setting on anti-islanding clearing time was not as clear. Again, the load power factor was always unity for these tests. A comparison of $100 \mathrm{~kW}$ load data at 1 , 0.95, and 0.9 diesel generator power factor settings, as shown in Figure 40, showed that somewhere in the middle - around 0.95-yielded the fastest trip times. More testing is necessary to verify these results.

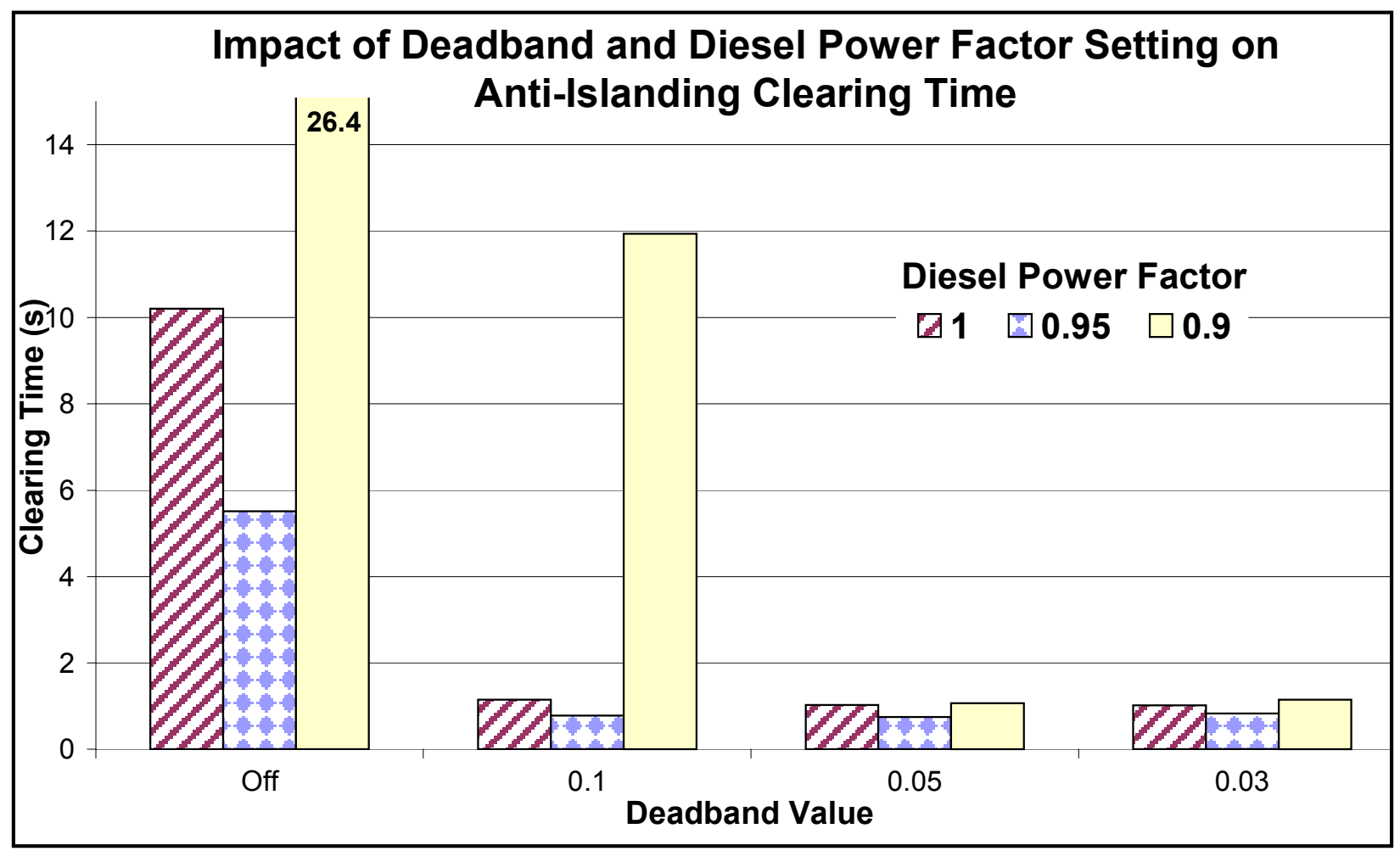

Figure 40. Power factor effect on anti-islanding loss of phase 
Last, tests for loss of phase on the grid side were conducted to examine single-phase islanding. Using the same setup and procedure with the diesel running at $50 \%$ capacity $(63 \mathrm{~kW})$ at unity power factor, the ASCO unit single-phase cease-to-energize response was tested by stepping the voltage on each phase of the grid simulator to zero. Even without the active anti-islanding protection enabled, the ASCO SLTS was able to immediately identify the loss of any single phase. The ASCO SLTS quickly tripped on a wide variety of protective functions. The longest trip time was still less than a quarter of a second.

A summary of the single-phase results is shown in Table 16. The varying trip times for phases may be caused by slight imbalances in the system. The ASCO tripping was significantly different from three-phase islanding because here the utility breaker and output autotransformer were still connected while the grid simulator de-energized a single phase.

Table 16. Summary of Loss of Phase Results

\begin{tabular}{lll}
\hline & \multicolumn{2}{c}{ Phase Step to Zero } \\
Phase & \multicolumn{1}{c}{ Average Trip Time } & \multicolumn{1}{c}{ Trip Function } \\
\cline { 2 - 3 } A & $0.0288 \mathrm{~s}$ & Rev current, overfreq \\
B & $0.184 \mathrm{~s}$ & Overfreq, over/undervolt \\
C & $0.0402 \mathrm{~s}$ & Undervolt, rev current \\
All three & $0.0195 \mathrm{~s}$ & Rev current, underfreq \\
\hline
\end{tabular}




\section{Summary of Testing Issues/ Recommendations to Writing Group}

- Some discussion of generic monitoring, measurement, and testing strategies and requirements could be useful in P1547.1. The file size, sampling rate, and correct sampling window were significant factors of testing that could be mentioned in P1547.1 not to dictate values or procedures but as advice and warnings of issues to be aware of to aid smooth and accurate testing.

- Some values from the P1547.1 draft standard were incompatible with the testing setup. The minimum required value for the end point, $\mathrm{P}_{\mathrm{U}}$, of the step function in the time tests was not practical for frequency testing. At $110 \%$ or $90 \%$ of the trip magnitude for the over and underfrequency time tests, the ASCO tripped on other protective functions. $\mathrm{P}_{\mathrm{U}}$ had to be reduced to isolate the frequency protection.

- Similarly, the voltage levels specified in the IEEE 1547 table (and the corresponding starting voltage level $\mathrm{P}_{\mathrm{b}}$ for the ramp and step functions of P1547.1) could not be achieved by the diesel generator without adjusting voltage regulator settings. Varying the diesel voltage by more than about $30 \mathrm{~V}(6.25 \%$ versus the IEEE worst-case settings at $50 \% /+20 \%$ ) caused the diesel to trip on "excess reverse VARs." This issue may prove problematic if tested in the field with actual generators.

- Care must be taken to test each parameter individually without other protective functions operating.

- The abnormal voltage and frequency testing was conducted only on all three phases simultaneously. IEEE P1547.1 Section 5.0 Design Tests describes how each phase should be individually tested. 


\section{References}

Bower, W.; Ropp, M. "Evaluation of Islanding Detection Methods for Utility-Interactive Inverters in Photovoltaic Systems.” SAND2002-3591. Albuquerque, NM: Sandia National Laboratories. November 2002.

Daley, J.M.; Siciliano, R.L. "Application of Emergency and Standby Generation for Distributed Generation: Part 1." Industrial and Commercial Power Systems Technical Conference 2002. May 5-8, 2002; pp. 138-150.

Daley, J.M.; Siciliano, R.L. "Application of Emergency and Standby Generation for Distributed Generation: Part 2." Industrial and Commercial Power Systems Technical Conference 2002. May 5-8, 2002; pp. 151-157.

IEEE 1547 Standard for Interconnecting Distributed Resources With Electric Power Systems. New York, NY: Institute of Electrical and Electronics Engineers, 2003.

IEEE P1547.1 Draft 2 Draft Standard Conformance Test Procedures for Equipment

Interconnecting Distributed Resources With Electric Power Systems. New York, NY: Institute of Electrical and Electronics Engineers, 2003.

Kroposki, B.; DeBlasio, R.; Galdo, J. "Distributed Power Program DER Pilot Test at the Nevada Test Site." NREL/TP-560-32063. Golden, CO: National Renewable Energy Laboratory. May 2002. 


\section{Appendix A. IEEE P1547D10 Reference Information}

Table A-1. Interconnection System Response to Abnormal Voltages

\begin{tabular}{|c|c|}
\hline $\begin{array}{c}\text { Voltage Range } \\
\left(\% \text { of Base Voltage }{ }^{a}\right)\end{array}$ & Clearing Time $^{b}(s)$ \\
\hline$V<50$ & 0.16 \\
\hline $50 \leq V<88$ & 2 \\
\hline $110<\mathrm{V}<120$ & 1 \\
\hline$V \geq 120$ & 0.16 \\
\hline
\end{tabular}

Table A-2. Interconnection System Response to Abnormal Frequencies

\begin{tabular}{lll}
\hline DR Size & \multicolumn{1}{c}{ Frequency Range (Hz) } & \multicolumn{1}{c}{ Clearing Time $^{\mathrm{a}} \mathbf{( s )}$} \\
\cline { 2 - 3 }$\leq 30 \mathrm{~kW}$ & $>60.5$ & 0.16 \\
& $<59.3$ & 0.16 \\
& $>60.5$ & 0.16 \\
$>30 \mathrm{~kW}$ & $<\{59.8-57.0\}$ (adjustable set point) & Adjustable 0.16-300 \\
& $<57.0$ & 0.16 \\
& \\
\hline Note (a) DR $\leq 30 \mathrm{~kW}$, maximum clearing times; DR $>30 \mathrm{~kW}$, default clearing times.
\end{tabular}




\section{Appendix B. Abnormal Frequency and Voltage Test Results}

Table B-1. Abnormal Frequency and Voltage Test Results

Ovial Num
1
2
3
4
5

Average

Setting

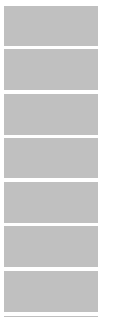

60.531

60.458

60.604

60.461

60.534
Magnitude

Trip Frequency $(\mathrm{Hz}$

5
Overfrequency Time

Trial Number

1

2

3

$4-40$

$5 \quad 39$

Underfrequency Magnitude

Trial Number

1
2
3
4
5

Trip Frequency $(\mathrm{Hz})$

59.301

59.311

59.298

59.312

59.284

Average

Setting

Required
Underfrequency Time

\begin{tabular}{|cc|}
\hline \multicolumn{2}{|c|}{ Underfrequency Time } \\
\hline Trial Number & Trip Time (s) \\
\hline 1 & 1.58 \\
\hline 2 & 1.48 \\
\hline 3 & 1.58 \\
4 & 1.57 \\
\hline 5 & 1.54 \\
\hline
\end{tabular}

Average

1.55

1.70
Fast Underfrequency Magnitude

Trial Number

Trip Frequency $(\mathrm{Hz})$

$$
\begin{aligned}
& 1 \\
& 2 \\
& 3 \\
& 4 \\
& 5
\end{aligned}
$$

Average

Setting

Overvoltage Magnitude

Trial Number
1
2
3
4
5

Average

Setting

57.000
56.987
57.000
57.000
56.987

56.995 57.000

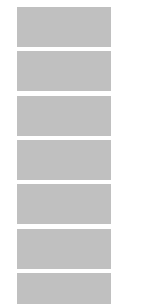

Fast Underfrequency Time

Trial Number

1

2

3

4

5

Average

Required
46.84

160.00
Trip Time (ms)

40.82

41.02

50.42

50.80

51.14 
Fast Overvoltage Magnitude

Trial Number

1.0

2.0

3.0

4.0

5.0
Trip Voltage (V)

501.7

499.8

501.7

501.7

502.2

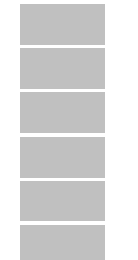

$\sqrt{2} \cdot$

5.0

$$
1.0
$$

2.0
Fast Overvoltage Time

Trial Number Trip Time (ms)

40.2

41.4

36.5

46.9

48.1

Average

501.4

Average

42.6

Setting

504.0

Required

160.0

Undervoltage Magnitude

Trial Number

1.0

2.0

3.0

4.0

5.0

Trip Voltage (V)

459.8

453.4

458.7

458.7

459.8

Average

Setting

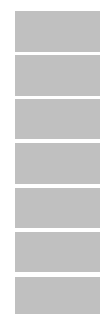

\section{Undervoltage Time}

Trial Number

Trip Time (s)

1.0

1.92

2.0

1.92

3.0

1.88

4.0

1.93

5.0

1.88

458.1 456.0

Average

1.91

Required

2.00

Fast Undervoltage Magnitude

Trial Number

1.0

2.0

Trip Voltage (V)

451.9

455.6

3.0

454.9

4.0

454.1

5.0

449.0

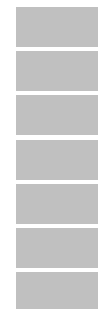

Fast Undervoltage Time

Trial Number

1.0

Trip Time (ms)

2.0

54.5

55.0

3.0

57.2

4.0

74.9

5.0

43.4

453.1

Average

446.0 Required

57.0

160.0 


\title{
Appendix C. ASCO Anti-lslanding Test Results
}

Table C-1. ASCO Anti-Islanding Test Results

\author{
NREL Test Data
}

$11 / 12 / 2002$

\section{Anti-Islanding Test}

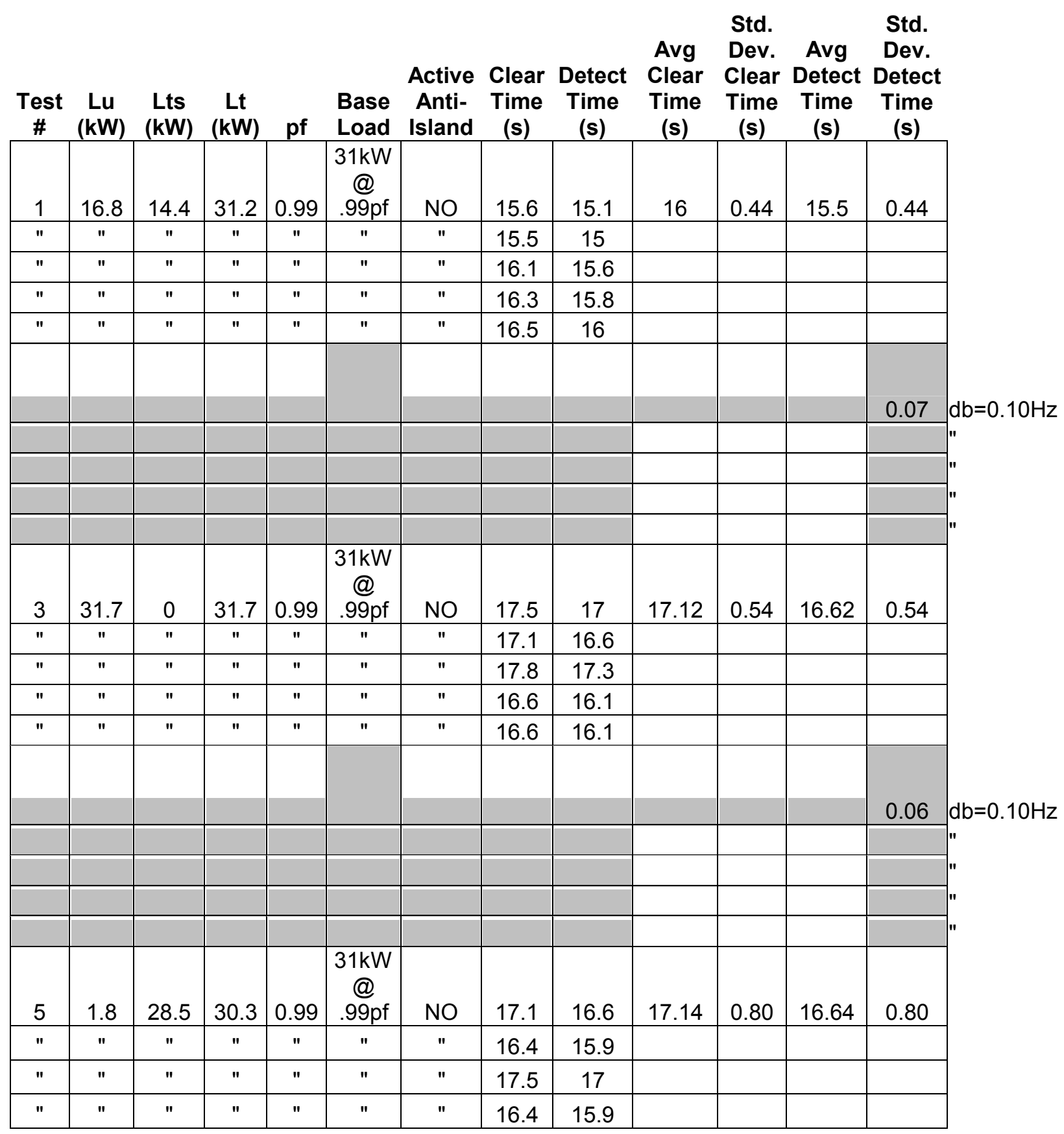




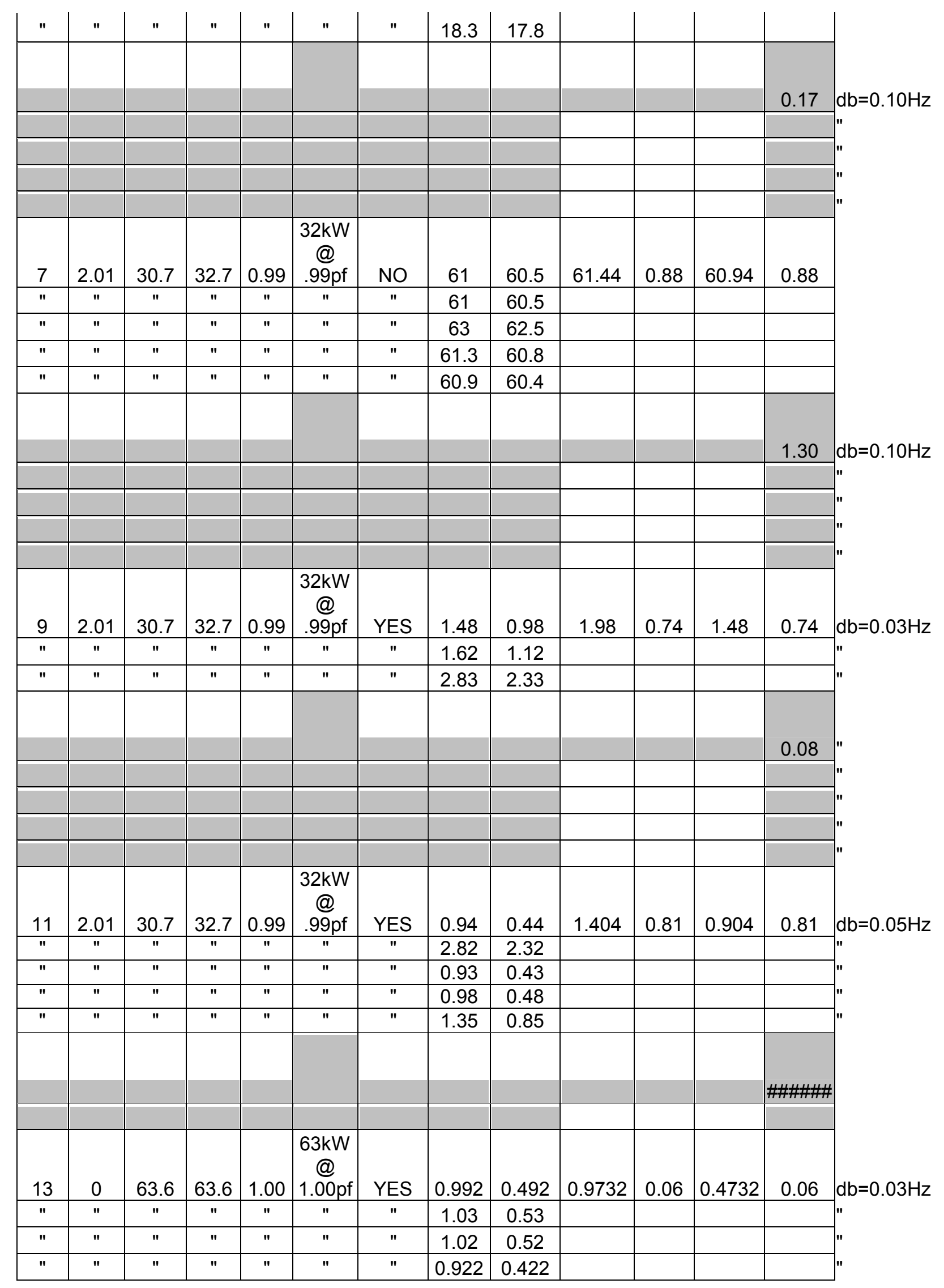




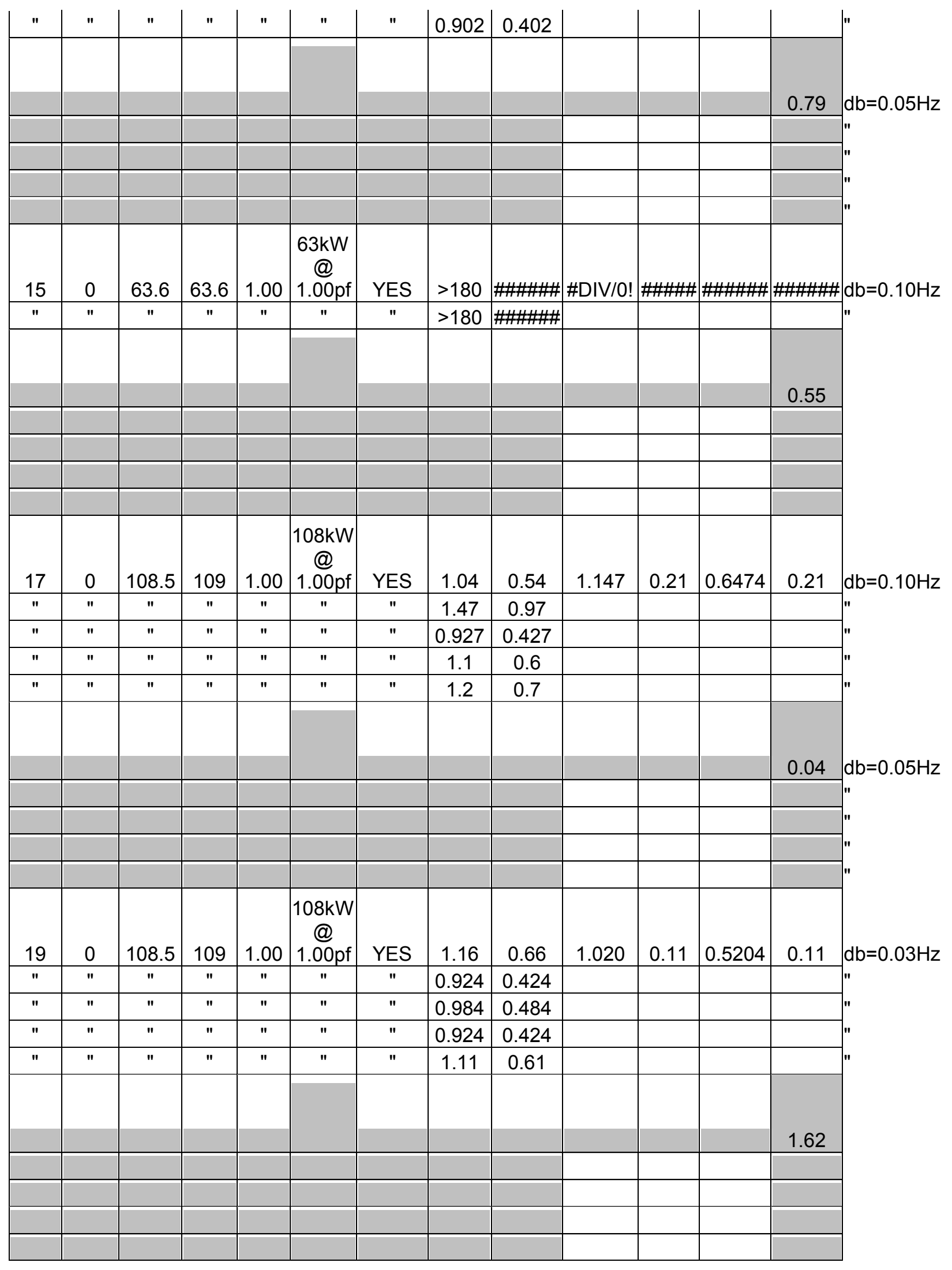




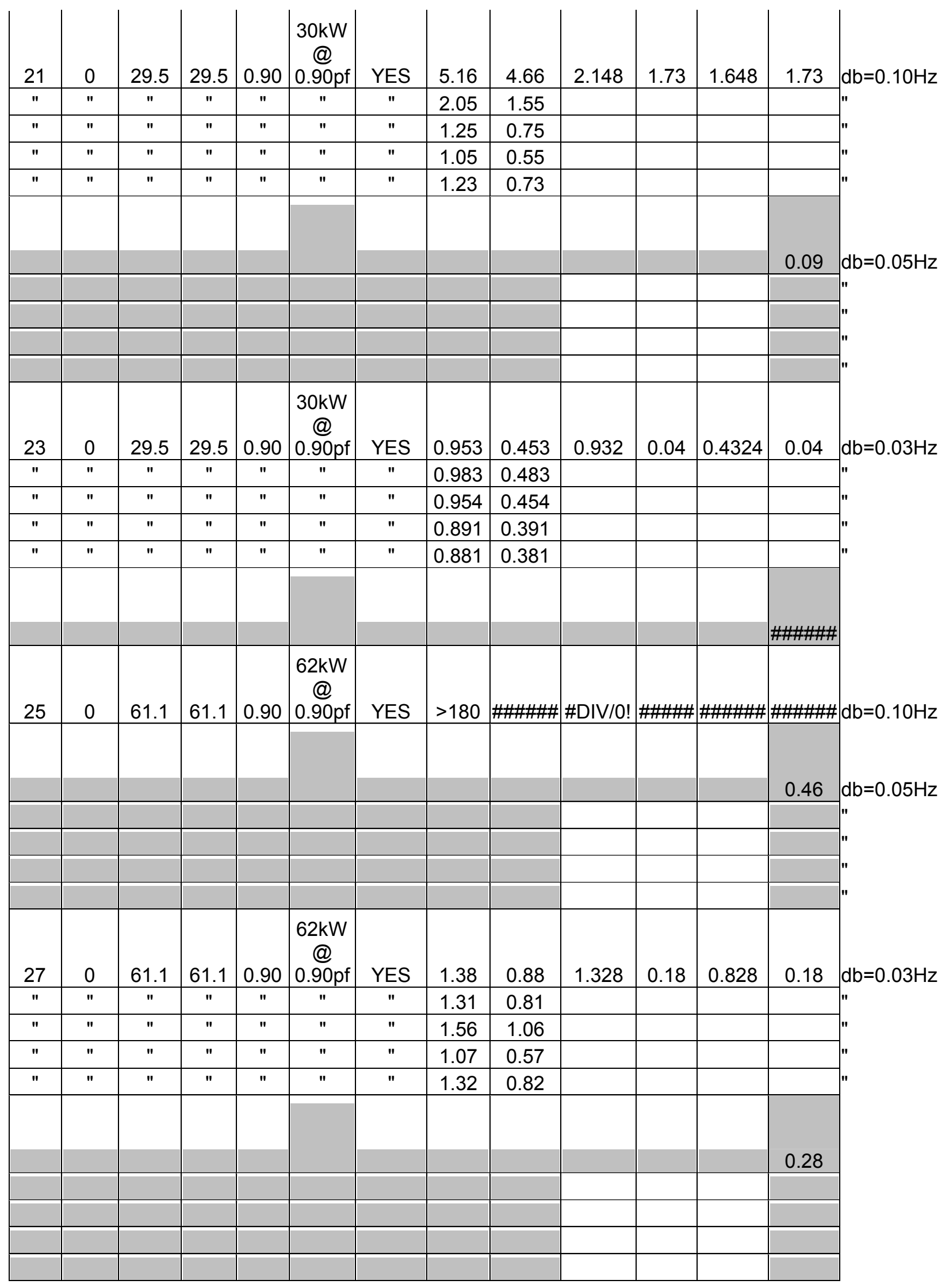




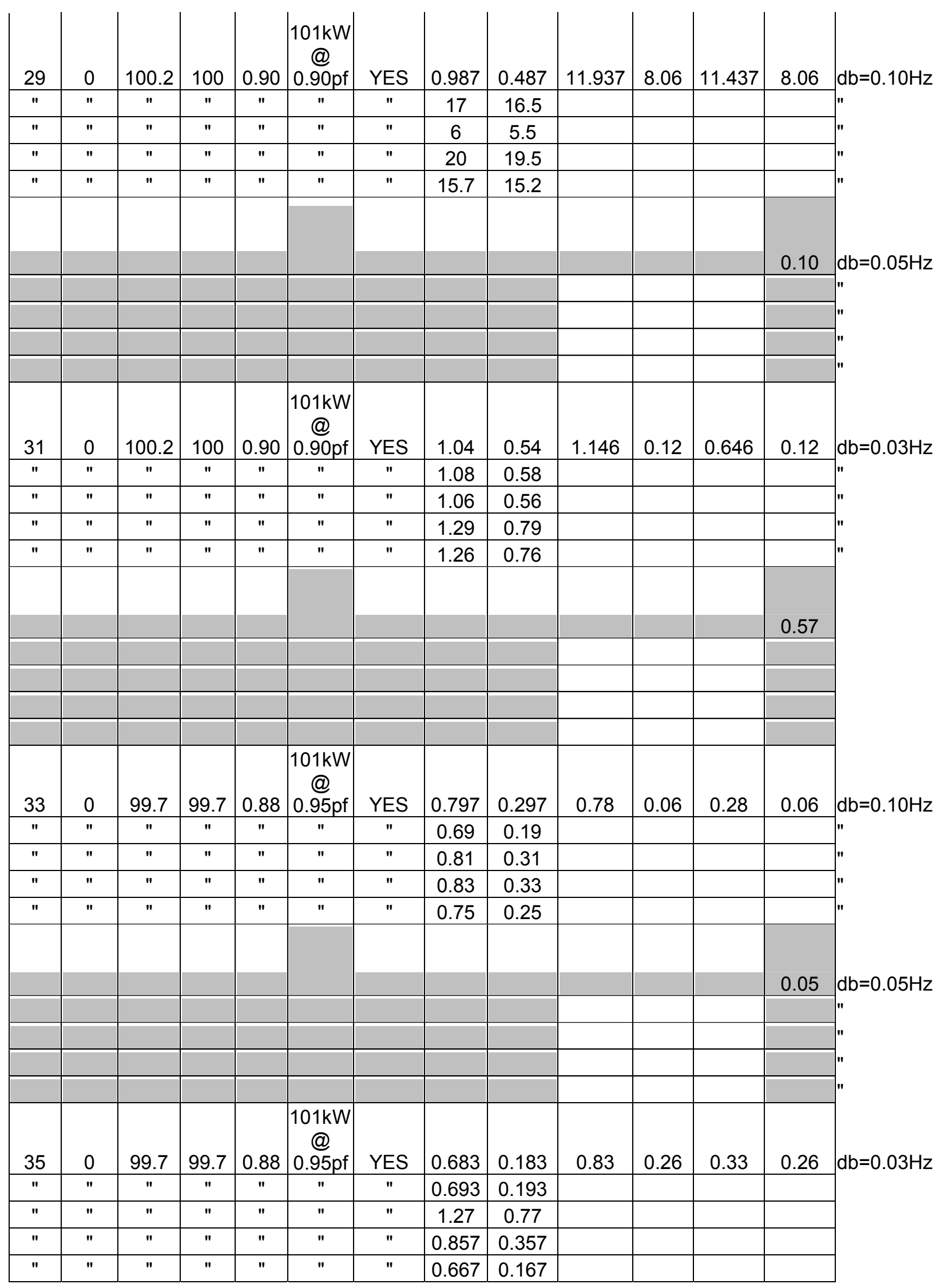




\begin{tabular}{|c|c|c|c|c|c|c|c|c|c|c|c|c|c|}
\hline & & & & & & & & & & & & 2.00 & \multirow{10}{*}{$\begin{array}{l}\mathrm{db}=0 \mathrm{~Hz} \\
V \mathrm{pk}=0.34 \\
50 \mathrm{~ms} \text { updt }\end{array}$} \\
\hline & & & & & & & & & & & & & \\
\hline & & & & & & & & & & & & & \\
\hline & & & & & & & & & & & & & \\
\hline & & & & & & & & & & & & & \\
\hline 37 & 0 & 63.9 & 63.9 & 1.00 & $\begin{array}{c}62 \mathrm{~kW} \\
@ \\
1.00 \mathrm{pf}\end{array}$ & YES & 0.76 & 0.26 & 1.03 & 0.40 & 0.53 & 0.40 & \\
\hline$"$ & $"$ & $"$ & $"$ & $"$ & \begin{tabular}{|c|} 
\\
\end{tabular} & $"$ & 1.4 & 0.9 & & & & & \\
\hline$"$ & $"$ & $"$ & $"$ & $"$ & $"$ & $"$ & 1.31 & 0.81 & & & & & \\
\hline$"$ & $"$ & $"$ & $"$ & $"$ & $"$ & $"$ & 1.22 & 0.72 & & & & & \\
\hline " & $"$ & " & $"$ & $"$ & $"$ & $"$ & 0.457 & -0.043 & & & & & \\
\hline & & & & & & & & & & & & \#\#\#\#\#\# & \multirow{6}{*}{$\begin{array}{l}\mathrm{db}=0 \mathrm{~Hz} \\
\mathrm{Vpk}=0.34 \\
100 \mathrm{~ms} \\
\text { updt }\end{array}$} \\
\hline 39 & 0 & 63.5 & 63.5 & 1.00 & $\begin{array}{c}63 \mathrm{~kW} \\
@ \\
1.00 \mathrm{pf}\end{array}$ & YES & 3.55 & 3.05 & 4.35 & 1.78 & 3.85 & 1.78 & \\
\hline$"$ & $"$ & $"$ & $"$ & $"$ & " & $"$ & 7 & 6.5 & & & & & \\
\hline$"$ & $"$ & $"$ & " & $"$ & $"$ & $"$ & 2.14 & 1.64 & & & & & \\
\hline$"$ & $"$ & $"$ & $"$ & $"$ & $"$ & $"$ & 4.47 & 3.97 & & & & & \\
\hline$"$ & $"$ & $"$ & $"$ & $"$ & $"$ & $"$ & 4.6 & 4.1 & & & & & \\
\hline & & & & & & & & & & & & 1.46 & \multirow{11}{*}{$\begin{array}{l}\mathrm{db}=\mathrm{OHz} \\
\mathrm{Vpk}=0.38 \\
100 \mathrm{~ms} \\
\text { updt }\end{array}$} \\
\hline & & & & & & & & & & & & & \\
\hline & & & & & & & & & & & & & \\
\hline & & & & & & & & & & & & & \\
\hline & & & & & & & & & & & & & \\
\hline 46 & 0 & 63.9 & 63.9 & 1.00 & $\begin{array}{l}63 \mathrm{~kW} \\
@ \\
1.00 \mathrm{pf}\end{array}$ & NO & $>180$ & & & & & & \\
\hline 47 & 0 & 63.9 & 63.9 & 1.00 & $\begin{array}{c}\text { 63kW } \\
@ \\
1.00 \mathrm{pf}\end{array}$ & YES & 1.007 & 0.507 & 1.11 & 0.13 & 0.61 & 0.13 & \\
\hline$"$ & $"$ & " & " & $"$ & " & " & 0.983 & 0.4832 & & & & & \\
\hline " & $"$ & $"$ & " & $"$ & $"$ & " & 1.288 & 0.788 & & & & & \\
\hline$"$ & $"$ & $"$ & $"$ & $"$ & $"$ & $"$ & 1.215 & 0.715 & & & & & \\
\hline " & $"$ & $"$ & $"$ & $"$ & $"$ & $"$ & 1.064 & 0.564 & & & & & \\
\hline
\end{tabular}

Note: Test Data showing \#\#\#\# - Unit did not trip, and test was terminated after $180 \mathrm{~s}$. 


\section{Appendix D. ASCO Single-Phase Anti-Islanding Test Result}

Table D-1. ASCO Single-Phase Anti-Islanding Test Results

NREL Test Data

Single-Phase Test

$\pm$

\begin{tabular}{|c|c|c|c|c|c|c|c|c|c|}
\hline Test \# & $\begin{array}{l}\text { Lts } \\
(k W)\end{array}$ & pf & Base Load & $\begin{array}{c}\text { Active } \\
\text { Anti- } \\
\text { Islanding }\end{array}$ & $\begin{array}{c}\text { Clear } \\
\text { Time (s) }\end{array}$ & $\begin{array}{c}\text { Average } \\
\text { Clear } \\
\text { Time (s) }\end{array}$ & $\begin{array}{l}\text { Std. Dev. } \\
\text { Clear } \\
\text { Time (s) }\end{array}$ & Trip Function & Fault Description \\
\hline 41 & 63.9 & 1.00 & 63kW@1.00pf & NO & 0.0175 & 0.0288 & 0.009 & Rev current, overfreq. & Phase A step to zero \\
\hline " & " & $"$ & " & " & 0.0375 & & & Rev current, overfreq. & " \\
\hline$"$ & $"$ & $"$ & $"$ & $"$ & 0.0224 & & & Rev current, underfreq. & $"$ \\
\hline$"$ & $"$ & $"$ & $"$ & $"$ & 0.0285 & & & Rev current, rev kW, overfreq & $"$ \\
\hline " & $"$ & $"$ & $"$ & $"$ & 0.0379 & & & Rev current, overfreq., undervolt & " \\
\hline & & & & & & & & & Phase B step to zero \\
\hline & & & & & & & & & " \\
\hline & & & & & & & & & $"$ \\
\hline & & & & & & & & & $"$ \\
\hline & & & & & & & & & $"$ \\
\hline 43 & 63.9 & 1.00 & 63kW @ 1.00pf & NO & 0.042 & 0.0402 & 0.012 & Undervolt & Phase C step to zero \\
\hline$"$ & $"$ & $"$ & " & $"$ & 0.052 & & & Undervolt, rev current & " \\
\hline$"$ & $"$ & $"$ & $"$ & $"$ & 0.0372 & & & Undervolt, rev current, underfreq. & $"$ \\
\hline$"$ & $"$ & $"$ & $"$ & $"$ & 0.0219 & & & Undervolt, rev current & $"$ \\
\hline$"$ & $"$ & $"$ & $"$ & $"$ & 0.0478 & & & Undervolt & $"$ \\
\hline & & & & & & & & & $\begin{array}{c}\text { Phase A } 20-\text { s ramp to } \\
80 \% \\
\end{array}$ \\
\hline 45 & 63.9 & 1.00 & 63kW @ 1.00pf & NO & 0.0203 & 0.0195 & 0.005 & Undervolt, underfreq. & $\begin{array}{c}\text { Three phases step to } \\
\text { zero }\end{array}$ \\
\hline$"$ & $"$ & $"$ & " & $"$ & 0.016 & & & Rev current, underfreq. & " \\
\hline$"$ & $"$ & $"$ & $"$ & $"$ & 0.0151 & & & Rev current, underfreq., overfreq. & $"$ \\
\hline$"$ & $"$ & $"$ & $"$ & $"$ & 0.0275 & & & Rev current, rev kW, UF, OF, UV & $"$ \\
\hline$"$ & $"$ & $"$ & $"$ & $"$ & 0.0185 & & & Rev current, UF, OF, UV & $"$ \\
\hline
\end{tabular}




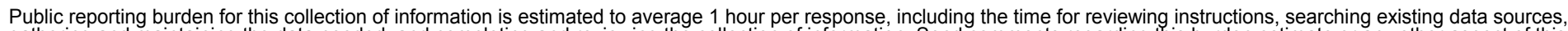

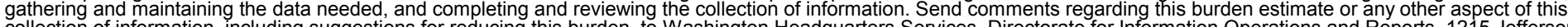
Davis Highway, Suite 1204, Arlington, VA 22202-4302, and to the Office of Management and Budget, Paperwork Reduction Project (0704-0188), Washington, DC 20503.
1. AGENCY USE ONLY (Leave blank)
2. REPORT DATE
September 2003
3. REPORT TYPE AND DATES COVERED
Subcontract report

4. TITLE AND SUBTITLE

Validation of IEEE P1547.1 Interconnection Test Procedures: ASCO 7000 Soft Load

Transfer System

5. FUNDING NUMBERS

DP03.1001

6. $\operatorname{AUTHOR}(\mathrm{S})$

B. Kroposki, S. Englebretson, C. Pink, J. Daley, R. Siciliano, and D. Hinton

7. PERFORMING ORGANIZATION NAME(S) AND ADDRESS(ES)

National Renewable Energy Laboratory

1617 Cole Blvd.

Golden, CO 80401-3393

9. SPONSORING/MONITORING AGENCY NAME(S) AND ADDRESS(ES)
8. PERFORMING ORGANIZATION REPORT NUMBER

NREL/TP-560-34870

10. SPONSORING/MONITORING AGENCY REPORT NUMBER

11. SUPPLEMENTARY NOTES

12a. DISTRIBUTION/AVAILABILITY STATEMENT

National Technical Information Service

U.S. Department of Commerce

5285 Port Royal Road

Springfield, VA 22161

13. ABSTRACT (Maximum 200 words)

This report presents the preliminary results of testing the ASCO 7000 Soft Load Transfer System according to IEEE P1547.1 procedures. The ASCO system interconnects synchronous generators with the electric power system and provides monitoring and control for the generator and grid connection through extensive protective functions. The purpose of this testing is to evaluate and give feedback on the contents of IEEE Draft Standard P1547.1 Conformance Tests Procedures for Equipment Interconnecting Distributed Resources With Electric Power Systems.

14. SUBJECT TERMS standards; testing; IEEE P1547.1; IEEE 1547; islanding; anti-islanding; Distributed Energy Resources Test Facility; distributed power; distributed generation; distributed energy resources; DP; DG; DER; International Electrical and Electronics Engineers; Distribution and Interconnection R\&D; National Renewable Energy Laboratory; NREL

17. SECURITY CLASSIFICATION OF REPORT Unclassified
18. SECURITY CLASSIFICATION OF THIS PAGE Unclassified
19. SECURITY CLASSIFICATION OF ABSTRACT

Unclassified
15. NUMBER OF PAGES

16. PRICE CODE

20. LIMITATION OF ABSTRACT

UL 